
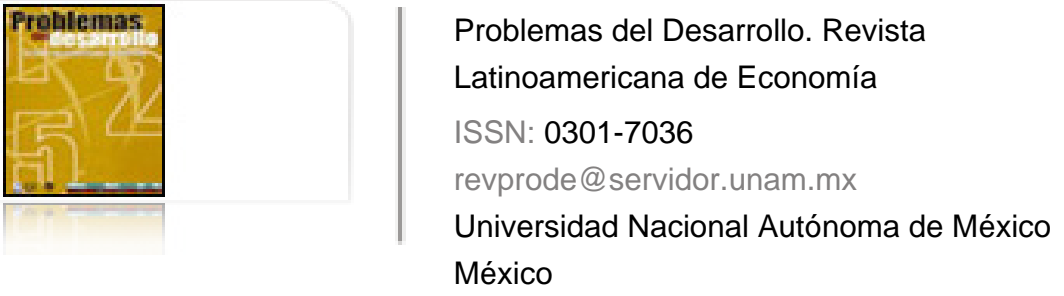

Dabat, Alejandro

LA CRISIS FINANCIERA EN ESTADOS UNIDOS Y SUS CONSECUENCIAS INTERNACIONALES Problemas del Desarrollo. Revista Latinoamericana de Economía, vol. 40, núm. 157, abril-junio, 2009, pp. 39-74

Universidad Nacional Autónoma de México

Distrito Federal, México

Disponible en: http://www.redalyc.org/articulo.oa? $\mathrm{id}=11820087006$

- Cómo citar el artículo

- Número completo

- Más información del artículo

Página de la revista en redalyc.org

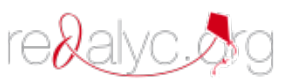

Sistema de Información Científica

Red de Revistas Científicas de América Latina, el Caribe, España y Portugal Proyecto académico sin fines de lucro, desarrollado bajo la iniciativa de acceso abierto 


\title{
LA CRISIS FINANCIERA EN ESTADOS UNIDOS Y SUS CONSECUENCIAS INTERNACIONALES
}

\author{
Alejandro Dabat*
}

Fecha de recepción: 4 de febrero de 2009. Fecha de aceptación: 5 de mayo de 2009.

\section{Resumen}

El presente artículo considera la crisis internacional basada en el sistema financiero estadounidense desde una perspectiva analítica que trata de unir tres aspectos íntimamente ligados en la generación y el desenlace de la misma: 1) La naturaleza de la crisis situada esencialmente en el sistema financiero de Estados Unidos, su relación con la especulación inmobiliaria y sus consecuencias internacionales, 2) El deterioro preexistente de la competitividad sistémica y la hegemonía de Estados Unidos desde comienzos del siglo actual; y 3) Los cambios neoeconómicos y geopolíticos mundiales de los últimos que determinan el actual reordenamiento del contexto internacional. En ese sentido, trata de unir los aspectos financieros, tecnoeconómicos y sociopolíticos de la crisis con la naturaleza de los grandes cambios mundiales que la misma implica. Palabras claves: Estados Unidos, crisis financiera, orden mundial, sistema financiero $y$ crisis.

* Investigador titular C de tiempo completo en el Instituto de Investigaciones Económicas de la Universidad Nacional Autónoma de México. Correo electrónico: dabat@servidor.unam.mx. 


\section{Abstract}

This article looks at the international crisis based on the U.S. financial system from an analytical perspective that tries to bring together intimately linked aspects in the generation and outcome of the same: 1) The nature of the crisis situated essentially in the U.S. financial system, its relationship with real estate speculation and its international consequences, 2) The pre-existing deterioration of systemic competitiveness and the hegemony of the United States since the beginning of the present century; and 3) The worldwide neo-economic and geopolitical changes in the latter which determine the present reordering of the international context. In that sense, it tries to bring together the financial, techno-economic and socio-political aspects of the crisis with the nature of the broad world changes this implies.

Key words: United States, financial crisis, world order, financial system, crisis.

\section{Résumé}

Cet article envisage la crise internationale découlant du système financier américain sous un angle analytique, tentant d'englober trois aspects étroitement liées dans son origine et son dénouement: 1) la nature de la crise touchant essentiellement le système financier des États-Unis, sa relation avec la spéculation immobilière et ses retombées internationales; 2) la détérioration préexistante de la compétitivité systémique et de l'hégémonie des États-Unis depuis le début de ce siècle; 3) les changements néoéconomiques et géopolitiques mondiaux qui déterminent l'actuel réagencement du contexte international. Dans ce sens, l'article tente de faire le lien entre les aspects financiers, techno-économiques et sociopolitiques de la crise et la nature des grands changements mondiaux qu'elle entraîne.

Mots clés: États-Unis, crise financière, ordre mondial, système financier et crise.

\section{Resumo}

O presente artigo considera a crise internacional baseada no sistema financeiro estadunidense de uma perspectiva analítica que trata de unir três aspectos intimamente ligados à geração e ao desenlace da mesma: 1) A natureza da crise situada essencialmente no sistema financeiro dos Estados Unidos, sua relação com a especulação imobiliária e suas consequências internacionais, 2) A deterioração pre-existente da competitividade sistêmica e a hegemonia dos Estados Unidos desde o começo do século atual; e 3) As mudanças neoeconômicas e geopolíticas mundiais dos últimos anos que determinam o atual reordenamento do contexto internacional. Nesse sentido, trata de unir os aspectos financeiros, tecnoeconómicos e sociopolíticos da crise com a natureza das grandes mudanças mundiais que a mesma implica.

Palavras-chave: Estados Unidos, crise financeira, ordem mundial, sistema financeiro e crise. 


\section{Introducción}

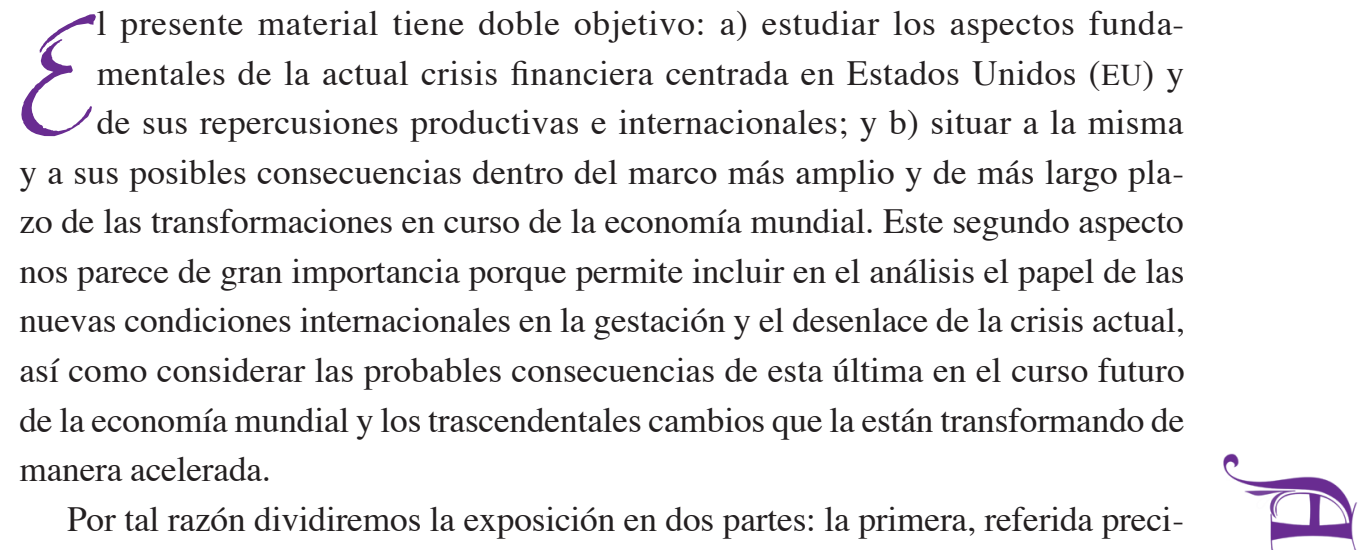
samente a la crisis en sí misma y las más probables consecuencias de la crisis sobre la economía mundial y los países en desarrollo y a su contexto económico general, y la segunda, la evolución general de la economía mundial durante la última década, incluyendo el comportamiento de Estados Unidos dentro de ésta y la relación de este último fenómeno con la crisis actual. Como se trata en todos los casos de problemas complejos que requieren cada uno un estudio particular, nos limitaremos a presentar someramente los mismos, apoyándonos en estudios anteriores y en la serie de intervenciones que hemos tenido en encuentros recientes sobre los temas señalados.

\section{PRIMERA PARTE}

\section{La actual crisis financiera y sus consecuencias productivas inmediatas}

Vista desde una perspectiva espacial, la actual crisis internacional es sobre todo una gran crisis de la economía de Estados Unidos, difundida ampliamente en el ámbito mundial en un nivel aún muy incierto, cuya magnitud dependerá tanto del grado de exposición de los diferentes países y regiones a los fenómenos que la generaron, como de las políticas defensivas que los mismos adopten y del aprovechamiento de las ventanas de oportunidad abiertas por la propia crisis. Pero también es un colapso del orden internacional que engloba y cuestiona aspectos económicos, sociales, políticos e institucionales propios del rumbo actual de la globalización, de la supremacía internacional de neoliberalismo, del propio curso de la economía del conocimiento (de la relación entre sus lados luminosos y oscuros) ${ }^{1}$ y, muy en particular, de la hege-

1 Por lado oscuro aquí nos referimos a innovaciones financieras como las obligaciones colateralizadas de deuda (CDO) basadas en el modelo Cúpula de Li, que posibilitaron el proceso 
monía mundial de Estados Unidos y el orden mundial de Bretton Woods establecidos durante su liderazgo.

\section{La especificidad de la crisis actual}

La actual crisis internacional se diferencia de casi todas las crisis económicas internacionales desencadenadas en los países capitalistas centrales, como las de 2001-2002 o la de 1990-1991, por ejemplo, para sólo citar las más recientes. La especificidad de la crisis actual no es tanto el resultado de un proceso de sobreacumulación de capital en los sectores productivos de punta, desencadenada en el plano financiero por el estallido de una burbuja especulativa bursátil centrada principalmente en esos sectores (Pérez, 2004), sino más bien una crisis financiera-bancaria de nuevo tipo, ${ }^{2}$ como veremos más adelante, gestada dentro de una coyuntura de crecimiento sostenido de la economía mundial, tanto de la producción y la inversión productiva como, en particular, de los sectores de punta del actual ciclo económico mundial.

El estallido de la crisis hipotecaria en Estados Unidos a mediados de 2007 parece no haber afectado sensiblemente al curso de la economía mundial hasta mediados de 2008, la cual continuó manteniendo altas tasas de crecimiento superiores a 5\% anual (UN, 2008) con niveles récord de inversión internacional directa cercanos al $30 \%$ anual anterior (WTO, 2008). El nuevo núcleo dinámico de la economía mundial (sector electrónico-informático) mantenía altas tasas de crecimiento al momento del estallido. Según Gartner, la consultora más reconocida de la industria electrónica, la producción de los componentes básicos de la misma (semiconductores) seguía manteniendo "un crecimiento sorprendentemente fuerte" aún en el tercer trimestre de 2008 (Deffree, 2008), y lo mismo señala la consultora IDC, para quien las ventas de microprocesadores para las computadoras personales continuaban creciendo a "niveles récord" hasta el mismo periodo (Business Wire, 2008).

Lo mismo puede observarse en la bolsa de Nueva York, al comparar el comportamiento de los índices NASDAQ (acciones de alta tecnología) y Dow Jones (conjunto

especulativo más amplio de la historia del capitalismo. Tales innovaciones resultaron de un arduo trabajo de investigación universitaria y combinación de ingeniería financiera y computación, que no puede dejar de ser considerado parte de la economía del conocimiento.

2 Por crisis bancaria entendemos las crisis originadas en la insolvencia generalizada del sistema bancario y la consiguiente paralización del crédito. En términos estrictos, Estados Unidos no vivió una crisis bancaria de ese tipo desde la ocurrida en los años treinta del siglo pasado (Marshall, 2009); pero aun en este caso no como causa principal del derrumbe económico, sino como resultado de la caída de Wall Street de 1929 (Kindleberger, Historia financiera de Europa, 1988). 
balanceado de acciones de diferentes esferas de negocios): existen relaciones muy distintas entre lo sucedido en 2001-2002 (la llamada crisis de Internet) y la de 2008, desencadenada a partir de la caída bursátil de septiembre de ese año, en la coyuntura de auge bursátil que precede a la caída así como a partir de esta misma. En el ciclo que culmina en el derrumbe de 2001-2002, los valores del NASDAQ se alejan más fuertemente de los del Dow Jones, tanto hacia arriba en el auge como hacia abajo en el desplome (ascenso y caída muchísimo más pronunciadas de las cotizaciones). En cambio, durante la crisis de 2008 no hay gran diferencia en el comportamiento de ambos índices en la fase ascendente del ciclo bursátil ni en la descendente.

A nuestro entender, ello se debe a que la crisis actual no puede reducirse estrictamente a ninguna de las tipologías anteriores. Como señalamos al comienzo de esta sección, la crisis de 2008 no sólo fue el resultado de una sobreacumulación de capital en sectores de punta, sino de la creciente desconexión entre la nueva economía financiera (colosal masa de sobreacumulación de capital-dinero especulativo en búsqueda de colocación lucrativa por cualquier medio) y de las dimensiones de la economía real, la demanda social y la inversión productiva en Estados Unidos y en la mayor parte del mundo. A partir del nuevo siglo, la gran sobreacumulación de capital dinerario tendió a centrarse en un nuevo tipo de sistema bancario desregulado (Gillian and David, 2007; Marshall, 2009) existente en potencia desde los orígenes del capitalismo informático y la globalización neoliberal, a partir de la contradicción profunda entre la fortaleza y dinamismo de la producción global y la nueva economía del conocimiento, y la fragilidad de un sistema financiero anárquico, cada vez más volátil e hipertrofiado. ${ }^{3}$

Este nuevo sistema financiero se estableció a partir de un conjunto de fenómenos nuevos integrados sistémicamente entre sí: la titularización y desregulación del crédito, la informatización de la circulación del dinero, la globalización financiera, los instrumentos financieros derivados, ${ }^{4}$ los nuevos fondos especulativos de inversión

3 Esta contradicción interna de la globalización había sido ya claramente percibida por Cox y Sinclair (1996, cap. 15) en su feliz expresión de "gobernancia sin gobierno". Con otras formas, numerosos autores, la han considerado, incluidos Dabat y Toledo (1999) y Dabat (2002).

4 Para los no economistas no resulta fácil comprender la naturaleza de los instrumentos "derivados", porque se trata de instrumentos muy complejos cuyo valor se basa (deriva) en la evolución del precio de otro activo "subyacente" (acción u otros títulos de deuda, cestas de acciones o títulos, bienes o incluso precio de otros instrumentos derivados, etcétera), cuya relación se establece mediante un acto especulativo de apuesta. Los derivados se multiplicaron de forma amplia desde la penúltima década del siglo pasado, supuestamente como medio de protección del contratante contra los riesgos de incertidumbre (cobertura) generados por la volatilidad de 
(Dabat y Toledo, 1999) y el enorme enriquecimiento rentístico-privado de amplios sectores de la población mundial favorecidos por la globalización, que acentuó el sesgo especulativo del capitalismo estadounidense y mundial conforme consideramos en la sección Las bases económicas y tecnológicas de la declinación de la segunda parte de este trabajo.

Ese proceso adquirió dimensiones mayores y a la postre incontrolables, a partir de la primera década del nuevo siglo, con la aparición de los nuevos instrumentos, instituciones y mecanismos especulativos originados sobre todo en Estados Unidos (sistema bancario paralelo desregulado), que elevaron de manera considerable el riesgo sistémico del conjunto del sistema financiero. Con los llamados CDO o SIV apareció un nuevo tipo de instrumentos derivados sintéticos o "empaquetados" de aún mayor complejidad y explosividad (cócteles de títulos muy diversos de naturaleza y calidades muy diferentes), asociados a nuevas reglas de funcionamiento del sistema financiero, que coincidió en tiempo con el mayor despliegue y el estallido extrabursátil de la burbuja hipotecaria.

La interacción entre ambos factores (causa estructural y detonante) se dio principalmente en el mercado inmobiliario de Estados Unidos, por ser el mismo donde más se expresaron y convergieron los factores mencionados. Pero a su vez, como veremos en la segunda parte del presente trabajo, la causa estructural mencionada (carácter del nuevo sistema financiero) encuentra sus raíces en algo aún más profundo en términos históricos, que es el proceso previo de declinación del capitalismo estadounidense ante la competencia internacional, atribuible en gran parte a su propia naturaleza socioinstitucional.

La alteración especulativa de los mercados inmobiliarios comenzó a gestarse en el ámbito internacional a partir de la última década del siglo pasado, como resultado del sostenido elevamiento especulativo de precios de la propiedad inmobiliaria en la gran mayoría de los países del mundo. Pero la burbuja inmobiliaria se convirtió en un fenómeno mucho más amplio a partir de las condiciones creadas por la crisis de 2000-2002 (The Economist, 2007). ${ }^{5}$ Como resultado de las grandes pérdidas bursáti-

los precios en la época de la desregulación de los mercados (swaps, futuros, opciones), pero terminaron siendo los principales instrumentos de la especulación financiera, como lo demuestra la conversión de los llamados Fondos de Protección (Hedge Funds) en las instituciones más fuertemente especulativas de la época.

5 La crisis de comienzos de siglo en Estados Unidos (2001-2002) generó tanto las condiciones económicas de expansión del mercado inmobiliario (reducción de tasa de interés por debajo de la tasa de inflación impulsada por la FED para reactivar la economía), como la reorientación de los fondos especulativos desde el mercado bursátil a los mercados inmobiliarios, aprovechando 
les de entonces y de la baja rentabilidad prevaleciente de los mercados especulativos tradicionales ${ }^{6}$, tuvo lugar una masiva reorientación internacional del capital especulativo hacia esos mercados. Pero este proceso, a su vez, "contaminó" profundamente a los nuevos paquetes financieros y, con ello, al conjunto del sistema de crédito así como al propio capital de las empresas, estableciendo un nexo directo entre la crisis de las hipotecas subprime y el fenómeno muchísimo más amplio de estallido general de los mercados financieros y de paralización internacional del crédito.

En principio, la crisis hipotecaria estadounidense pudo ser detonante de la crisis por características muy particulares del mercado inmobiliario de ese país, que es de gran tamaño, debido tanto al altísimo nivel relativo de los precios del suelo ${ }^{7}$ como a los elevados niveles de ingresos de la población o a la amplia difusión de la vivienda propia. Esos factores fueron muy acentuados coyunturalmente por el excepcional auge de la demanda y la construcción inmobiliaria provocadas tanto por la prosperidad de la última década del siglo pasado, como por la fuerte reducción de los costos hipotecarios y facilidades de adquisición, que permitieron incorporar al mercado una gran cantidad de adquirentes de bajos ingresos. El crecimiento del mercado hipotecario y el de los precios de la vivienda en Estados Unidos pueden verse en las gráficas 1 y 2 , que en conjunto (al multiplicar el volumen de ventas por el alza de precios) elevaron el valor de la propiedad inmobiliaria (stock) de cerca de 10 billones de dólares en el año 2000 a aproximadamente 20 billones en 2005, en sólo cinco años. En términos de flujos (valor anual de las operaciones inmobiliarias) ello significó un

los niveles históricos relativamente bajos de los precios de los activos inmobiliarios en comparación a otros activos. Para Marshall (ibid.), ello resultó de una estrategia explícita de la FED y otras entidades gubernamentales para "guiar el capital especulativo hacia el sector de bienes raíces, mediante incentivos fiscales e impositivos, y la innovación financiera que permitía extender créditos hipotecarios en nuevas formas a nuevos agentes".

6 La especulación financiera internacional se concentró a fines del siglo pasado en operaciones "de arbitraje" entre los diferentes tipos de cambio y tasas de interés de las economías nacionales en proceso de integración a la globalización, encabezado por los Hedge Funds. Sucesivos ataques contra las monedas nacionales se centraron respectivamente en Inglaterra y Europa Occidental (1992), México y Argentina (1995), Asia Oriental (1997) o Rusia (1998). Pero la estabilización monetaria de esos países redujo su exposición ante tales ataques especulativos, al conducir la especulación internacional hacia los mercados bursátiles de "alta tecnología" ("exuberancia irracional" que culminó en la crisis de 2001-2002). Como pasó con los mercados monetarios nacionales, la persistente caída de los valores bursátiles desde 2001 redujo los beneficios especulativos, lo cual provocó un nuevo desplazamiento hacia los mercados inmobiliarios.

7 Como resultado de la altísima renta del suelo que prevalece en Estados Unidos, los precios de la propiedad inmobiliaria en ese país son muchísimos más altos que los prevalecientes, por ejemplo, en México, para un mismo tipo de edificación. 
salto de $4.4 \%$ del producto interno bruto (PIB) estadounidense a $6.3 \%$ entre los mismos años (The Economist, 2007).

Gráfica 1

Mercado inmobiliario en Estados Unidos, ventas e inventarios

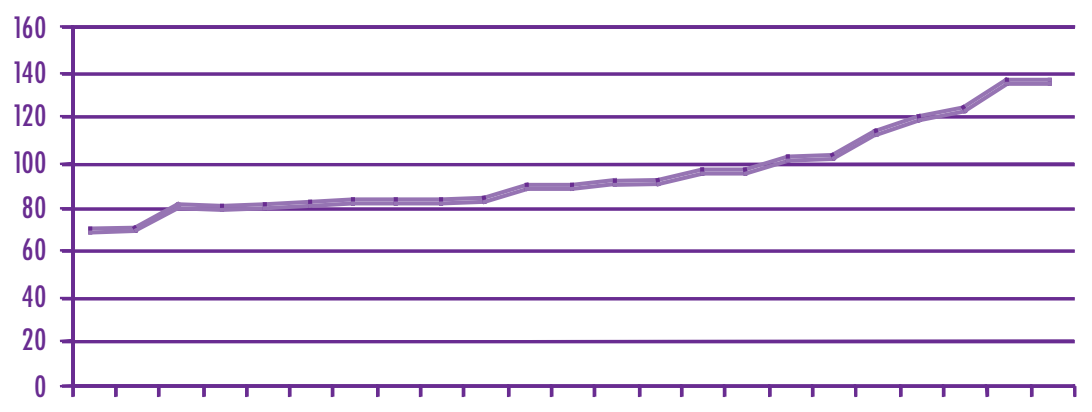

$\begin{array}{llllllllllll}1985 & 1987 & 1989 & 1991 & 1993 & 1995 & 1997 & 1999 & 2001 & 2003 & 2005 & 2007\end{array}$

Risina burden

Fuente: Hermes, economic Situation \& Outlook, Quarter 4, 2007.

\section{Gráfica 2}

Elevamiento de los precios de la vivienda en Estados Unidos entre 2000 y 2006

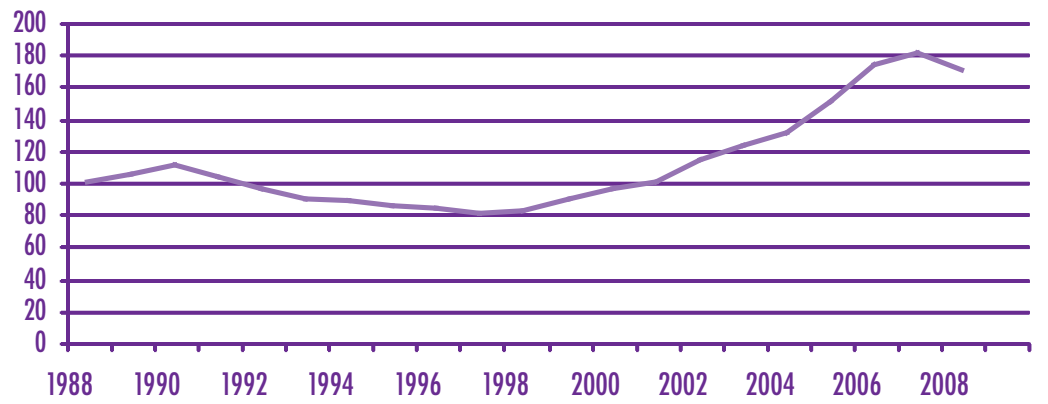

Fuente: Hermes, Economic Situation \& ORueciokdela zirviend 2007.

Pero la gravedad de la crisis hipotecaria de Estados Unidos no estribó en el tamaño del mercado hipotecario y de su eslabón más débil (la magnitud de los créditos subprime o de baja calificación crediticia), sino en su relación con el nuevo sistema financiero y los mecanismos de integración en él. Estados Unidos fue el centro originario del nuevo sistema financiero de titularización del crédito, de la globalización 
financiera, también el país que contó con los mayores índices de profundización financiera (relación entre activos financieros y el PIB, mayor peso de los instrumentos derivados y, en particular, a partir de la crisis de 2001-2002, de sus formas más peligrosas de contagio carácterísticas del shadow banking system que incorporaron letales mecanismos de diversificación y transmisión de riesgo sistémico en gran escala en el conjunto del sistema financiero y la economía, conforme veremos en el apartado Colateralización y "estructuración" del crédito, sistema bancario oculto y dinámica de la crisis de esta primera parte).

El peso del nuevo sistema financiero en Estados Unidos queda patente en el cuadro 1 expresado en relación con el PIB, al nivel de los activos financieros y no tradicionales (monto de acciones, bonos, derivados en general y otros instrumentos titularizados de crédito tales como las hipotecas convertidas en documentos negociables). El Fondo Monetario Internacional (FMI) subestima considerablemente los montos de las columnas B y, sobre todo, C. ${ }^{8}$ Pero a pesar de ello, el cuadro sirve para demostrar tanto la enorme magnitud relativa de los activos financieros y los instrumentos derivados frente a la economía real en Estados Unidos y el mundo, como la enorme concentración de los mismos en el país del norte que sólo se encuentra en magnitud cercana de muy pocos países del mundo, como es el caso de Gran Bretaña y Australia.

Cuadro 1

Activos financieros e instrumentos derivados en relación con el PIB, 2006 (miles de millones de dólares)

\begin{tabular}{lcccccc}
\hline & \multicolumn{2}{c}{ A) PIB } & \multicolumn{2}{c}{ B) Activos financieros } & \multicolumn{2}{c}{ C) Instrumentos derivados* } \\
& Total & $\%$ & Total & $\%$ & Total & $\%$ \\
\hline Estados Unidos & 13.195 & 100 & 50.185 & 280,34 & 100.738 & 663,47 \\
Resto del mundo & 35.010 & 100 & 101.606 & 190,22 & 142.596 & 307,30 \\
\hline Total & 48.204 & 100 & 151.791 & 214,89 & 243.334 & 504,80 \\
\hline
\end{tabular}

Fuente: Global Financial Stability Report, FMI, septiembre 2007.

* No incluye derivados sobre acciones y commodities. Si se suman estos rubros, los montos totales de derivados de créditos, el total mundial habría ascendido en 2007 a 548 miles de millones, más otros a 596 de derivados teóricos OTC (sobre liquidación de instrumentos) que habría que incluir.

8 Según el Banco Internacional de Pagos, hacia finales de 2007 el valor notional (supuesto) del conjunto de los instrumentos derivados mundiales alcanzaba 596 trillones de dólares estadounidenses (596 miles de millones en español), que es una cifra cerca de 10 veces superior al del PIB mundial y acorde con las relaciones establecidas en el cuadro 1, cerca de 20 veces para el caso de Estados Unidos. 
La enorme concentración del capital dinerario y ficticio ${ }^{9}$ en Estados Unidos fue acrecentada por la gran aceleración de los flujos externos de inversión pública y privada, destinada esta última principalmente a la adquisición de títulos públicos (letras del Tesoro fundamentalmente) y privados (bonos y acciones), depósitos bancarios, títulos hipotecarios y derivados entre otros, con muy escasa participación de la inversión directa que se fue reduciendo desde $30.6 \%$ de la inversión extranjera total a $9.8 \%$ en 2006 (CRS, Report for Congress, 2008). Junto con la muy fuerte declinación de la inversión directa, destaca el gran incremento de la compra externa de activos públicos estadounidenses como los bonos del Tesoro de Estados Unidos, que pasó de un promedio de 4 5\% en los años 1999-2000, a cerca de 24\% en 2006 (CRS, Report for Congress, ibid.). En este rubro sobresale la participación creciente de China en la adquisición masiva de títulos de deuda pública del gobierno de Estados Unidos, ${ }^{10}$ como pieza central de su política cambiaria orientada a la preservación de la subvaluación del yuan.

Cuadro 2

Flujos externos de capital hacia Estados Unidos 1996-2006 (miles de millones de dólares)

\begin{tabular}{cccc}
\hline Año & Total & Flujos públicos totales & Flujos privados totales \\
\hline 1996 & 551 & 127 & 424 \\
1997 & 707 & 19 & 688 \\
1998 & 424 & -20 & 444 \\
1999 & 740 & 44 & 697 \\
2000 & 1.047 & 43 & 1.004 \\
2001 & 783 & 28 & 755 \\
2002 & 768 & 14 & 654 \\
2003 & 829 & 249 & 581 \\
2004 & 1.440 & 395 & 1.045 \\
2005 & 1.204 & 259 & 995 \\
2006 & 1.590 & 440 & 1.419 \\
\hline
\end{tabular}

Fuente: Department of Commerce, Survey of Current Business, julio de 2007, p. 67.

9 En la terminología del nuevo sistema financiero, se denomina "notional value" al valor teórico (ficticio o supuesto) del instrumento original de crédito que se utiliza para calcular los pagos realizados sobre el mismo. Esta cantidad, generalmente, no cambia de manos y, por tanto, sólo es teórico. En el contexto de un swap de tipos de interés, el importe teórico del principal es la cantidad especificada en la que se basa el intercambio de los pagos de intereses derivados de los instrumentos principales. Durante cada periodo, las tasas se multiplican por el importe teórico del principal, para determinar el valor de cada contraparte.

10 En 2008 China era el principal poseedor de títulos del Departamento del Tesoro de Estados Unidos seguido por Japón con $19 \%$, el Reino Unido con $12 \%$, los centros bancarios del Caribe con $7 \%$ y los exportadores de petróleo con $6 \%$. 
Colateralización y "estructuración" del crédito, sistema bancario oculto y dinámica de la crisis

Pero la especificidad de la crisis hipotecaria y de sus mecanismos de difusión al conjunto del sistema financiero y la economía real en un nivel tan grande no pueden comprenderse sin considerar brevemente el intrincado despliegue de los nuevos mecanismos y los agentes de la titularización, colateralización y estructuración del crédito desde sus nuevas formas de CDO o VIS, ${ }^{11}$ así como de los agentes e instituciones que las producen y distribuyen en el conjunto del sistema financiero (nuevo modelo de "originar para distribuir") y su unidad en un nuevo sistema bancario paralelo.

En la práctica, el nuevo modelo contribuyó a la formación y al estallido de la burbuja hipotecaria, luego siguió la mecánica que se narra a continuación (Ballabriga y Mena, 2008). Los grandes acreedores hipotecarios originarios (bancos e instituciones que otorgan créditos hipotecarios) venden los títulos hipotecarios a "originadores" bancarios y no bancarios, quienes los transfirieren a los bancos de inversión o instituciones hipotecarias como Ranie Mae o Freddy Mac. A su vez, éstos titularizan los créditos hipotecarios y los transfieren a grandes intermediarios empaquetadores (bancos de inversión, entre otros), quienes les dan forma como CDO o VIS, respaldados por dictámenes favorables de las agencias calificadoras de riesgo que les asignan las más altas calificaciones crediticias, y de seguros otorgados por Monoline, muy débilmente reguladas, que llegaron a asegurar 3.3 trillones de dólares estadounidenses en 2006, contando sólo con un capital de respaldo de casi 34 billones estadounidenses de capital propio (Association of Financial Guaranty Insurers, 2008).

Ello resultó en un amplísimo proceso de venta o intercambio de estos títulos con intermediarios financieros muy diversos (bancos, aseguradoras, fondos de inversión o de pensiones, etcétera) y todo tipo de empresas (Ballabriga y Mena, 2008). De esa manera, por ejemplo, el acreedor hipotecario efectivo se disocia del deudor con el que deja de tratar, y la deuda se integra en un paquete muy amplio y complejo de títulos de deuda que de hecho mezcla dinero "bueno" (en sentido de garantizado) con dinero "malo", donde es prácticamente imposible distinguir el uno del otro.

11 Los CDO son un tipo de títulos sintéticos, consistentes en paquetes estructurados de títulos de deuda de origen y calidad crediticia muy distintas, con los cuales los emisores (grandes intermediarios financieros) distribuyen el riesgo entre los compradores, sin que éstos puedan distinguir dentro de los mismos los tramos senior (de primer nivel o AAA), de los instrumentos de baja o muy baja calidad crediticia. Los VIS son títulos sintéticos más flexibles, también emitidos por grandes intermediarios financieros (introducidos por City Group en 1998), que admiten reinversiones en sus activos en portafolio y que se construyen al combinar la toma de créditos a corto plazo con tasa de interés baja, con colocaciones a largo plazo a tasas más altas. 
Ese tipo de relación cenagosa se extiende mucho más allá de los títulos "contaminados" por los créditos hipotecarios sin pagar o en peligro de default, en la medida que extiende la incertidumbre a lo largo de toda la cadena de pagos, incapacitada para conocer la localización de dichos títulos. En el ámbito de los intermediarios financieros tiene mucha importancia el reingreso masivo de la banca comercial al mercado del crédito titularizado, del que habían sido marginados por los fondos de inversión durante la primera etapa del proceso de titularización de fines del siglo pasado, también denominado, por esa razón, de "desintermediación bancaria" (Dabat y Toledo, 1999, cap. 1). ${ }^{12}$ Los grandes bancos comerciales regulados, por entidades formalmente independientes, afiliadas o patrocinadas por los propios bancos (Gilliany David, 2007), se suman a los nuevos fondos de inversión encabezados por los edge funds y los equity funds, junto con la vasta red de jugadores que operan al margen de toda regulación pública (emisores, titularizadores, empaquetadores, compradores, canjeadores, calificadores, aseguradores).

La suma de los viejos y nuevos jugadores dentro del nuevo tipo de juego especulativo a gran escala conforman el denominado shadow banking system (o sistema bancario desregulado y oculto), ${ }^{13}$ que se caracteriza por operar fuera del sistema financiero reglamentado por el Estado e, incluso, al margen las hojas de balance de gran parte de sus principales participantes (caso de los afiliados descentralizados de los grandes bancos regulados) (Gillian y Davies, 2007). Con esas características, este sistema bancario paralelo y oculto pasó a convertirse, por la magnitud de sus activos, en el principal sistema bancario del país con activos que en 2007 alcanzaban los 10,500 miles de millones de dólares (Barr, 2008), superiores a los menos de $10,200^{14}$ de la banca comercial regulada y equivalentes a aproximadamente unas tres cuartas partes del PIB estadounidense.

12 Entre 1970 y 1993, la participación de los bancos comerciales en el sistema financiero de Estados Unidos cayó de $39 \%$ a $25 \%$ del total, mientras la de los fondos de inversión pasaba de $22 \%$ a 47 \% (Dabat y Toledo, 1999).

13 Según el connotado periodista de Financial Times, Bill Gross, cabeza del Pinco Assets Management Group, al nuevo sistema se le llama "shadow banking system (traducimos del inglés) debido a que ha permanecido oculto por años, intocado por la regulación, y ha sido capaz de empaquetar mágica y místicamente préstamos de baja calidad, de modo que sólo los brujos de Wall Street lo pueden explicar" (Gillian y Davies, ibid.).

14 Según el US Statitistical Abstract, los activos de la banca comercial (regulada), incluyendo los activos de las sucursales en el exterior de la banca estadounidense, alcanzaba en 2007 11,176 miles de millones de dólares. Como los activos de los bancos estadounidenses en el exterior eran de 1,004 miles de millones en ese mismo año (Board of Governors de la FED, 2008) los activos de la banca regulada en el país alcanzaban la cifra mencionada de 10,172 miles de millones de dólares. 


\section{La transmisión de la crisis a la economía real}

Dada la gran magnitud del mercado inmobiliario y del enorme tamaño del shadow banking system y los instrumentos financieros "tóxicos" que difunde, la crisis inmobiliaria y financiera tuvo un enorme impacto en el conjunto de la economía estadounidense y - por ende - internacional, que inundó los balances empresariales del mundo con activos incobrables o de calidad completamente incierta. A partir del estallido de la burbuja hipotecaria a comienzos de 2007 (suspensión de pagos de los compradores de vivienda subprime ante el derrumbe del precio de sus viviendas y el alza de las tasas de interés), cayó el conjunto del mercado hipotecario, casi inmediatamente el bancario y la bolsa de valores, lo siguió el crédito interbancario y comercial que alimenta a corto plazo el funcionamiento cotidiano de la economía. Siguió la extensión internacional de la crisis al sistema bancario y las bolsas de valores, las primeras manifestaciones de caída del consumo, la producción y el empleo y los primeros planes de rescate que siguieron al estadounidense, que ya supera ampliamente los mil millones de dólares y se espera que duplique más esa cantidad por las enormes sumas requeridas para el salvamento de la banca, las grandes empresas productivas y las decenas de millones de deudores hipotecarios y de trabajadores despedidos.

Este proceso de crisis hipotecaria, financiera y productiva se ahondó por las consecuencias del adicional desplazamiento a enorme escala del capital especulativo internacional desde los mercados hipotecarios hacia los de los commodities en general, ${ }^{15}$ y del petróleo en particular, sobre todo a partir de 2005-2006. Ello condujo a los precios del crudo de 70-80 dólares por barril en la segunda mitad de 2007, a cerca de 160 dólares a mediados de 2008, antes de dar lugar al posterior desplome (estallido de la nueva burbuja) que los llevó a menos 50 dólares en noviembre de ese año. ${ }^{16} \mathrm{Tal}$ fenómeno, que afectó negativa o positivamente a los diferentes países conforme a su

15 La especulación en los mercados de commodities comenzó en 2004, y siguió la tendencia ascendente de la demanda y los precios internacionales, para elevarse fuertemente desde 2005, cuando comenzaron a caer los precios de los inmuebles. Como parte de ese proceso, los fondos invertidos en los mercados especulativos de futuros se elevaron desde cantidades que fluctuaban en cifras cercanas a los 10,000 miles de millones de dólares entre 1999 y 2003, a 40 en 2004, a cerca de 90 en 2005, a 120 en 2006, 160 en 2007 y a bastante más de 180 en el primer trimestre de 2008 (The Wall Street Examiner, 2008), lo que implica un crecimiento cercano a 2000\% en sólo una década que condujo a una cifra cerca de tres veces superior al PIB mundial. En lo que hace a los mercados de productos agrícolas involucrados, la inversión especulativa habría pasado de 25,000 millones de dólares en noviembre de 2007 a 55,000 en abril de 2008, afectó a más de la mitad del valor de las cosechas de maíz, soya y trigo de Estados Unidos (Wilson, 2008).

16 A pesar de esta caída generalizada del petróleo y las commodities, los precios internacionales continuaban siendo altos en 2008 en relación con los anteriores de 2003. 
posición en los mercados de commodities, golpeó en especial a la economía de Estados Unidos en el momento del estallido de su crisis, y generó nuevas preocupaciones sobre los peligros de la inflación primero y de la deflación después, como la sufrida en este último caso por la economía japonesa en la última década del siglo pasado (The Economist, 2008).

En síntesis, parece claro que Estados Unidos y el mundo han entrado en otra gran crisis, que afectará sobre todo a EU tanto en el corto plazo (por sus grandes consecuencias sobre el empleo y el quebranto empresarial), como el largo plazo, por el enorme endeudamiento público y privado que deberá asumir el país. También es claro que estamos ante una costosísima crisis terminal del sistema titularizadoespeculativo de crédito, como parte de una reorientación de la economía mundial hacia una economía mucho más regulada (Nourimi, 2008). En cambio, se tiene muy poca certidumbre de la magnitud y duración del proceso recesivo en Estados Unidos y de su extensión internacional, que son temas sobre los que existen muy variadas opiniones. Sin embargo, creemos que esto último no dependerá tanto de lo que suceda dentro de la propia economía de EU, sino de lo que pase en el ámbito de la economía mundial en su conjunto, en los avances tecnoeconómicos y socioinstitucionales y en la continuidad del crecimiento de los nuevos países y regiones emergentes y de su incidencia sobre el curso general de la economía internacional, cuestión que nos conduce al problema mucho más amplio del papel que está cumpliendo y tiende a cumplir Estados Unidos como potencia mundial.

\section{SEGUNDA PARTE}

\section{El contexto internacional más amplio de la crisis económica de EU}

Partimos de la hipótesis de que la crisis actual de Estados Unidos tiene lugar dentro del marco mucho más amplio de la decadencia de su economía nacional y de su hasta hace muy poco indiscutida hegemonía mundial, ante sus propias limitaciones estructurales e históricas para afrontar la competencia de nuevas potencias ascendentes o en proceso de resurgimiento, como son los casos de China, India, Rusia o del conjunto de los países de Asia Oriental y de otros en desarrollo (Dabat, 2005). Por dicha razón consideraremos por separado el proceso histórico que dio lugar a ese proceso, las bases tecnoeconómicas, financieras y sistémicas (de su modalidad de capitalismo nacional), para concluir con la erosión de su hegemonía mundial en la que se condensan los fenómenos anteriores. 


\section{Las raíces de la crisis estadounidense}

La base productiva del orden mundial comandado por Estados Unidos ha sido socavada por la emergencia de esas fuerzas, a partir de las mismas tendencias generadas por la globalización y el desarrollo de las economías del conocimiento y el aprendizaje articulado respecto de redes informáticas y cadenas productivas internacionales de diferente tipo, alentadas por variadas formas de rentas extraordinarias (Dabat, Rivera y Sztulwark, 2007), por nuevos procedimientos de la división internacional del trabajo, ${ }^{17}$ movilidad internacional de personas y de ideas, procesos de integración regional y políticas públicas activas de países en desarrollo que están dando una nueva forma a la globalización. A ello se le suman otros fenómenos como la recuperación de Rusia, la profundización de la crisis energética resultante tanto de las mayores necesidades de energía provocadas por la actual convergencia eléctrica-electrónica como de la crisis ambiental mundial y del agotamiento histórico de los métodos de energía basada en las fuentes no renovables y altamente contaminantes.

Como se ha expresado en trabajos anteriores (Dabat, 2005; Dabat y Morales, 2007 y Dabat y Melo, 2008), este reordenamiento se expresa sobre todo en tres hechos significativos: a) la crisis de la primera etapa de la globalización, caracterizada por la hegemonía absoluta de Estados Unidos y la primacía indiscutida del neoliberalismo dentro del marco del capitalismo informático-global; b) la emergencia de hecho de un nuevo orden mundial, basado en un nuevo tipo de globalización con formas institucionales diferentes (mayor peso de la regulación pública, preocupaciones por la inclusión social y mayor importancia de los procesos de integración regional), así como distintas relaciones internacionales de poder, que cuestionan la propia base de funcionamiento del capitalismo neoliberal estadounidense; y c) el gradual desplazamiento del centro cíclico económico mundial desde Norteamérica y Europa Occidental hacia Asia y en particular Asia Oriental, como resultado de la integración del nuevo papel internacional de China, la Asociación de Naciones del Sudeste Asiático (ASEAN, por sus siglas en inglés), India, Rusia y los países islámicos de Medio Oriente.

La actual crisis financiera de EU y sus repercusiones productivas e internacionales deben ser vistas como consecuencia de los procesos expuestos y como un factor fundamental del despliegue de los mismos en un nivel de profundidad y direccional abierto que puede dar lugar a diferentes opciones económicas, sociales, políticas y

17 Nos referimos aquí a la rearticulación de la división global del trabajo desarrollada en la última década, para incorporar nuevos procesos de integración regional y los nuevos requerimientos mundiales de productos básicos, energéticos y alimentos. 
espaciales de desarrollo que afecten de manera sustancial el curso actual de la globalización. Como se ha expresado antes (Dabat, 2005), la primera etapa de la globalización (o globalización neoliberal) culminó a principios de este siglo con la aparición de una crisis estructural histórica del papel internacional de EU. Los primeros síntomas de ese cambio aparecieron durante la crisis de 2001-2002 y la recuperación ulterior, que dio lugar a un gran cambio en las relaciones internacionales (ascenso de China, India y Rusia, drástico cambio de los términos de intercambio en favor de los países en desarrollo, productores de bienes primarios, y transformación del nuevo capitalismo financiero para dar lugar a la mayor y más compleja plétora de capital especulativo en la historia del capitalismo).

El estallido de la gran burbuja especulativa del NASDAQ en 2000 hizo tambalear el liderazgo tecnológico y productivo de Estados Unidos, en el corazón mismo de su superioridad económica, política y militar mundial. Después de 20 años de dirigir la gran oleada mundial de crecimiento desencadenada por la revolución informática, la economía estadounidense se sacudió por obra de una crisis de sobreacumulación de capital que tuvo su centro, precisamente en la producción informática (sector clave de la oleada ascendente del nuevo capitalismo) en la bolsa de valores, como sucedió casi siempre en la historia del capitalismo. Sin embargo, ello se tradujo en muy distintas expresiones internacionales con profundidad, duración y consecuencias muy diferentes en los distintos países y regiones.

Poco a poco, a partir de 2003, la economía de Estados Unidos comenzó un claro proceso de recuperación, con un crecimiento del PIB superior a 4\% anual en 2003, una rentabilidad del capital de más de 7\% en el mismo año y una productividad del trabajo que en 2002 y 2003 creció a una tasa promedio de 4.7\% (Dabat y Morales, 2007). Dicha recuperación estuvo apoyada en un nuevo impulso y profundo de la revolución informática y la división global del trabajo, como lo explican Dabat y Ordóñez (2009). Sin embargo, como se señaló en su momento, fue un proceso corto y débil, que no pudo sobrellevar adecuadamente los desafíos de la aceleración y profundización del desarrollo chino (asociado a la creciente integración de Asia Oriental), de la acelerada emergencia económica de India o del renacimiento de la economía y el poderío rusos.

\section{Las bases económicas y tecnológicas de la declinación}

Dentro de ese contexto, la rápida recuperación de la economía estadounidense de 2003-2004 fue seguida por una leve desaceleración del crecimiento del PIB a partir de 2005 (BEA, 2007). Si bien la rentabilidad de la gran empresa transnacional no 
dejó de crecer por obra de sus inversiones y redes internacionales (sólo aminora su dinamismo), dichos logros se ven en gran parte neutralizados por la creciente pérdida de competitividad del conjunto de la economía estadounidense frente a los países orientales y asiáticos comandados por China, en un proceso que también arrastrará a los socios comerciales de EU, integrantes del Tratado de Libre Comercio de América del Norte (TLCAN), con particular inclusión de México.

La pérdida de posiciones comerciales de Estados Unidos incluye también la mayor parte de las industrias de alta tecnología, como a casi todas las del sector electrónico-informático (Dabat y Ordóñez, 2009), al software (Export IT, 2008) ${ }^{18} \mathrm{o}$ a los servicios de telecomunicaciones (Ordóñez, 2008). En lo referente a industria electrónica en especial, la continuidad de la caída es particularmente fuerte frente a China y los países más dinámicos de Asia Oriental. Ello resalta sobre todo en el caso de las computadoras (en las que el nivel de producción nacional bajó $42 \%$ entre 2000 y 2007), y alcanza a otros sectores de importancia estratégica central como el instrumental electrónico (caída del orden de $12 \%$ entre esos mismos años) e incluso (en términos relativos a la producción mundial) a semiconductores (el sector estrella de la industria electrónica estadounidense), en el que la producción estadounidense se mantiene en 2007 al mismo nivel de 2002 (el año más bajo de la crisis de 2001-2002) a un nivel del orden de los 35 mil millones de dólares (Export IT, 2006).

La pérdida de competitividad internacional, sobre todo si consideramos a los sectores de alta tecnología en que se produjo, provocó un creciente déficit comercial como se muestra en el cuadro 2.

Pero el mismo fenómeno también condujo a un crecimiento más lento del crecimiento económico, especialmente en lo que se refiere a sus principales, nuevos y formidables competidores, que implicó fuertes pérdidas de posiciones del país dentro de la economía mundial en el nivel del PIB (fuerte reducción de la participación de Estados Unidos dentro de la producción mundial). En el cuadro 3 se muestra la dimensión de esta pérdida en general (porcentaje de disminución), y en relación con Asia Oriental e India (niveles y porcentajes comparados), presentamos las cifras

18 En 2007 las exportaciones registradas de software de EU (2,676 millones de dólares) no habían alcanzado aún el nivel del año 2000 (2,728 millones) y su crecimiento se concentra completamente en los países del TLCAN, India (como parte del creciente intercambio sectorial con ese país) y otras naciones de América Latina, sin que ello llegue a contrarrestar el déficit con Asia Oriental y Europa, que es algo completamente consistente con la información que suministran Dabat y Ordóñez (2009). Como se plantea en este último, los montos de las exportaciones registradas son mucho menores a las reales, pero sirven como un indicador de tendencia, especialmente en comparación con el vertiginoso crecimiento de las exportaciones que registra India. 
Gráfica 3

Exportaciones e importanciones de bienes y servicios de Estados Unidos 2000-2007 (millones de dólares a precios corrientes)

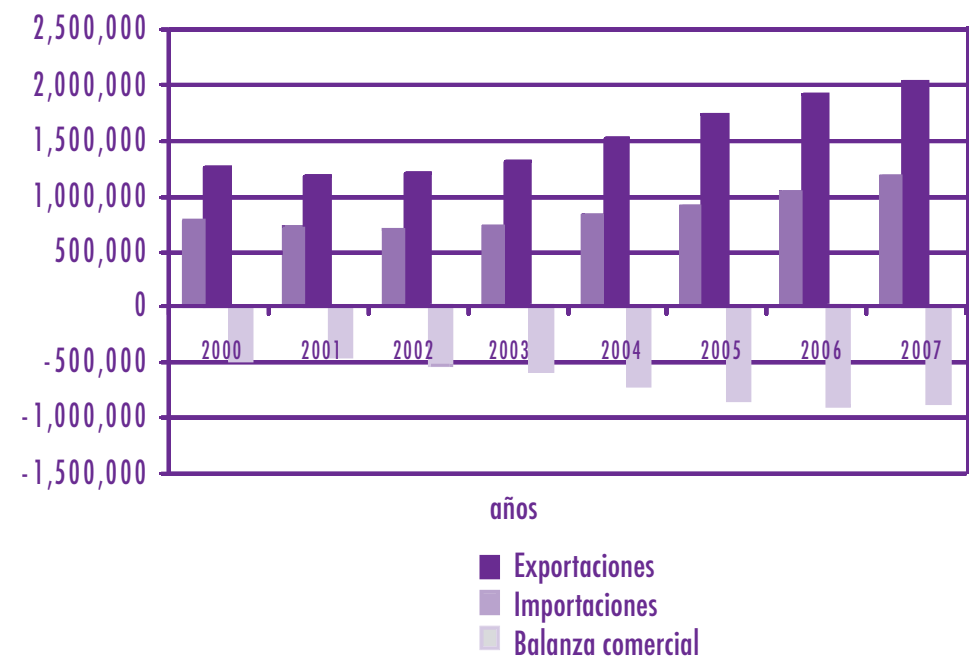

del producto en precios de paridad adquisitiva (PPP) para eliminar la distorsión que genera la gran subvaluación de la mayoría de las monedas asiáticas respecto con el dólar.

Cuadro 3

PIB-PPP de América del Norte y Asia Oriental e India 2000 y 2007 (billones de dólares)

\begin{tabular}{|c|c|c|c|c|}
\hline & \multicolumn{2}{|c|}{2000} & \multicolumn{2}{|c|}{2007} \\
\hline & Montos & $\%$ & Montos & $\%$ \\
\hline Asia Oriental e India & 10,784 & 25.9 & 20,589 & 31.7 \\
\hline América del Norte & 11,656 & 28.0 & 14,712 & 22.7 \\
\hline Mundial & 41,583 & 100.0 & 64,903 & 100.0 \\
\hline
\end{tabular}

Fuente: Elaboración propia con base en FMI.

* Asia Oriental incluye China, Hong Kong, Japón, Corea del Sur, Taiwán y países de la ASEAN.

Un factor esencial de tal pérdida de competitividad es la reducción de la brecha científica y tecnológica mundial que separaba a Estados Unidos de sus principales competidores. Tal factor, que es evidentemente importante por sí mismo, pasa a ser junto al desarrollo educacional un factor central de la competitividad creciente de los países de bajos costos laborales y altos niveles educacionales relativos a los países asiáticos, como factor de reducción de sus costos laborales unitarios y de la 
generación de rentas económicas extraordinarias de aprendizaje (Dabat, Rivera y Sztulwark, 2007; Dabat y Ordóñez, 2009) que compiten eficientemente con las rentas tecnológicas en sentido estricto. Tal reducción fue muy grande en electrónica e informática frente a los países más dinámicos de Asia, sobre todo de China, Corea y Taiwán, o a India en software (ibid.), sin contar a Japón, que tiene por sí mismo niveles muy cercanos a los de EU en muchos subsectores. En otros nuevos campos científicos como nanotecnología ${ }^{19}$ o biotecnología, el acercamiento favoreció a los países europeos y asiáticos (incluyendo a China) que compiten con Estados Unidos en niveles muy cercanos (CRS, Report for Congress, 2008).

La superioridad de EU en materia de conocimiento sólo se mantiene de manera clara en ciertos aspectos como el número de universidades de primer nivel o de publicaciones y autores citados o en sectores de la investigación y desarrollo (R\&D) como el militar (que absorbe 16\% del total de la inversión estadounidense) o el financiero (Ernst, 2008). Pero entre 1986 y 2003 la participación del país en la R\&D mundial cae de $46 \%$ en 1986 a $37 \%$, el número de investigadores de $43 \%$ a $29 \%$ y el del egreso de doctores de $52 \%$ a $22 \%$ (ibid.) $;{ }^{20}$ mientras se acentúa la importancia de los investigadores y graduados extranjeros, China superaba a Estados Unidos en número de ingenieros graduados en su país (Gereffi, Wadhwa, y Rissing, en prensa), aunque todavía no en calidad. Habría que agregar que EU sufre de una crisis de educación básica por carencias de su sistema educativo nacional y una creciente dependencia de científicos, ingenieros y técnicos extranjeros.

Como resultado de las ventajas productivas de naciones emergentes, una parte creciente de las actividades de investigación y desarrollo estadounidense (como de Europa Occidental y Japón) está siendo relocalizada en países en desarrollo (Atkin-

19 En nanotecnología, las universidades estadounidenses llevan de lejos la delantera en registro de patentes (Toledo, 2008). Pero este indicador podría no ser el más adecuado por el carácter prematuro o de baja calidad de muchos registros en muy diversos sectores (EPO, 2009) o por la desmedida importancia que se da a patenttes en el sistema institucional de EU. Pero al pasar a otros indicadores reales más conectados con la producción, no se advierte claramente tal superioridad. En nanoelectrónica, el sector más importante de la economía mundial por volumen de demanda e importancia estratégica (Dabat y Ordoñez, 2009), predominan Fujitsu, Samsung, la Agencia Japonesa de Ciencia y Tecnología, Hewlett Packard y Phillips. En energía lo hacen Japón, Corea y EU en ese orden, En salud, la Unión Europea, EU, China y Rusia (Toledo, ibid.). En cuanto a inversión pública, a pesar de la disparidad de información existente, parece claro que desde los primeros años del nuevo siglo Asia Oriental marcha a la cabeza (Lux Research, 2004; Commission of the European Communities, 2004) y que, según la segunda de las fuentes citadas, la Unión Europea habría sobrepasado a Estados Unidos.

20 Ernst sostiene que China podría superar en número de doctores a Estados Unido hacia 2010. 
son, 2004; UNTACD, 2006). La importancia de la relocalización de actividades de investigación puede ejemplificarse en Intel que tiene situada cerca de la mitad de sus 20 laboratorios en Asia como India (Bangalore, el más importante de todos), Malasia (Penang) o China. Al nivel de las 50 principales corporaciones trasnacionales que controlan los estándares mundiales de tecnología de la información y las comunicaciones, 25 siguen siendo estadounidenses, 12 europeas, ocho japonesas y cinco de otros países, dentro de una tendencia cada vez más desfavorable a EU por incremento de las redes globales de producción de base principalmente asiática (Ernst, ibid.).

En el plano social, destaca el debilitamiento relativo del mercado interno de EU, atribuible tanto a la creciente polarización social y el empobrecimiento de amplios sectores de la población como a un descenso relativo del consumo de las familias (véase la gráfica 4). Este fenómeno es paradójicamente compatible con un consumismo desmedido basado casi de manera exclusiva en el crédito y la publicidad, que reduce a casi cero el ahorro de las familias y anuncia un empobrecimiento bastante mayor como consecuencia de la actual crisis del crédito y el derrumbe de los ingresos generados por la desocupación, la caída del salario real y la reducción del patrimonio familiar por la crisis inmobiliaria.

Gráfica 4

Consumo en Estados Unidos

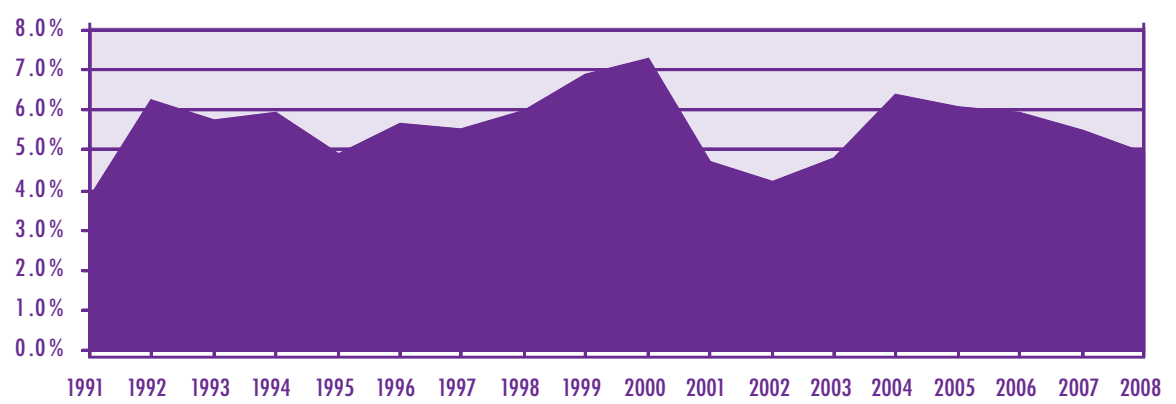

Fuente: www.bea.com.

La reducción del ahorro de las familias en los últimos años adquiere dimensiones enormes como puede verse en la gráfica 5, especialmente a partir de fines de la década pasada y, sobre todo, de 2005.

La acentuación de la desigualdad social es producto del enorme enriquecimiento de una amplia capa de la población, favorecido por el neoliberalismo y los recortes impositivos de George W. Bush, junto con el estancamiento o caída de los ingresos de los trabajadores y miembros de las distintas minorías de la población. Según The 
Gráfica 5

Ahorro de Estados Unidos como porcentaje del ingreso disponible

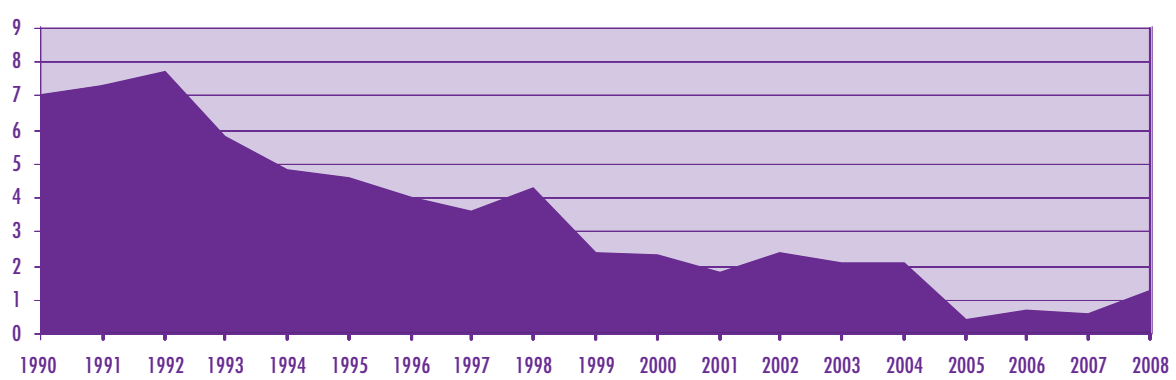

Fuente: www.bea.com.

Economist (2008), 20\% de la población elevó sus ingresos de 44\% a 50\% del ingreso nacional entre 1973 y 2000 y $1 \%$ de mayores ingresos controlaba hace pocos años $17 \%$ de la riqueza nacional, contra $17 \%$ de $80 \%$ de los hogares. La misma fuente señala que los ingresos de los más altos niveles gerenciales (CEO) pasaron a ser de 40 veces más elevados que el promedio de los trabajadores en 1980 a 400 veces más altos en la actualidad. Éste es sin duda un gran factor de descontento social y una de las fuerzas que explica el amplio triunfo electoral de un candidato negro y reformista como Barack Obama a la presidencia de su país.

Al debilitamiento del mercado interno, cabe agregar el deterioro de la infraestructura (puentes, carreteras, redes eléctricas, represas, aeropuertos, canales, edificios públicos o redes de comunicación) estudiado por Dalton (2008) o GAO (2008 y 2009), que incluye la nueva infraestructura informática (Irons, 2008; Baller y Lide, 2006). Ello estuvo directamente vinculado a la caída del gasto público total en el sector, desde cerca de $2.5 \%$ del PIB en 1950 a casi la mitad en 2006, a costa de catástrofes como la ruptura de los diques de Nueva Orleáns, del colapso del gran puente de Minneapolis, de los grandes cortes de energía entre el Medio Oeste y Nueva York o de la pérdida de posiciones internacionales en la extensión y calidad de las redes de comunicación de banda ancha. ${ }^{21}$

Pero el factor central que cada vez más debilita al país en el ámbito internacional es la acentuación de los aspectos más negativos de la modalidad de capitalismo

21 Según Baller y Lide (2006), el indiscutible predominio de Estados Unidos a comienzos de los noventa del siglo pasado concluyó en la era de la banda ancha y la extensión de la fibra óptica, cuando su posición internacional cayó al cuarto lugar mundial en 2001 y hasta el lugar 19, según ciertas encuestas, a mediados de la década (lugar 15 en velocidad en 2006 según la OCDE). 
financiero-especulativo de Estados Unidos ya considerados, en asociación a formas cada vez más anacrónicas de institucionalidad y cultura neoliberal. Este fenómeno también se da al interior de la propia organización productiva, como es el caso de la sociedad anónima estadounidense y la preeminencia del accionario absentista sobre la administración productiva y de la rentabilidad especulativa de corto plazo sobre la de largo plazo (Porter, 1998). Tal fenómeno fue reforzado por el creciente apalancamiento de la inversión productiva en sí misma y por el peso cada vez más grande de la exposición de la empresa a las adquisiciones hostiles de carácter especulativo promovidas por los Equity Funds, ${ }^{22}$ que acompañó al boom especulativo del mercado financiero entre 2004 y 2007.

Al nivel de la población, se expresó en el consumismo desmedido de un gran sector de la población, que tendió a financiar cada vez más sus gastos personales mediante el endeudamiento y a expensas del ahorro, a pesar del enorme crecimiento del ingreso de los estadounidenses ricos o en proceso de enriquecimiento, sustentado en la acentuación de la polarización social tan grande como la señalada anteriormente. Este enorme crecimiento de la riqueza privada tendió a acumularse de forma masiva en la esfera de la inversión financiera especulativa, tanto a expensas del financiamiento directo del consumo y de la propia inversión productiva, ${ }^{23}$ dando lugar a tendencias parasitarias muy fuertes que afectaron de manera muy sensible a la economía, a la sociedad y a los valores morales de los sectores acomodados de la población.

La presión exterior del sistema especulativo de crédito y el desvío de capitales hacia la especulación condujeron a los niveles históricos de apalancamiento, sobreendeudamiento y especulación señalados que, en conjunto, contribuyeron al desacoplamiento entre las esferas financiera (dineraria) y tecnoproductiva de la economía nacional. Tal factor implicó a su vez una enorme carga, tanto sobre la capacidad innovativa de la empresa estadounidense como sobre el liderazgo científico y tecnológico del país, planteando una contradicción muy fuerte entre las bases productivas del capitalismo informático y la economía del conocimiento y una superestructura financieraespeculativa cada vez más retardataria que terminó por golpear demoledoramente a

22 Según Wikipedia, Estados Unidos contaba en 2007 con $71 \%$ del capital mundial invertido en equity funds.

23 Aunque encabezado por EU, el fenómeno expuesto tuvo un alcance internacional muy amplio asociado a la acentuación de la desigualdad social en el mundo entero, promovida por la globalización neoliberal, que generó el enorme excedente improductivo de riqueza que estuvo en la base del descomunal crecimiento del capital-dinero especulativo en el ámbito mundial, elevado muy por encima de las demandas internacionales de inversión productiva. 
la producción misma. Como resultado de ello, las tendencias al sobreapalancamiento $\mathrm{y}$ al gasto por encima de las posibilidades de las personas, las empresas y el propio Estado condujeron tanto al progresivo debilitamiento del núcleo básico original del propio sistema financiero interno (banca comercial regulada) como a la posición cada vez más deficitaria del país en sus diferentes cuentas externas, expresada en una deuda externa formidable, incrementada por los costos políticos, económicos y militares derivados de un intento infructuoso por mantener la hegemonía mundial del país y de sus círculos de poder más reaccionarios.

\section{Los costos de la hegemonía}

Como señalamos al final de la sección anterior, a los factores estructurales ya expuestos que estuvieron en la base de la crisis se le sumó el enorme costo del esfuerzo político, económico y militar del gobierno republicano de George W. Bush para preservar un tipo de hegemonía mundial que comenzaba a desmoronarse en los hechos. Pero también se dieron los costos económicos, políticos y culturales del sostenimiento de la gran coalición conservadora que llevó a Bush al poder, conformada por los remanentes del viejo complejo industrial-militar, los intereses petroleros tradicionales, el nuevo capital financiero especulativo, el fundamentalismo religioso de siempre y la nueva derecha intelectual globalista y belicista ${ }^{24}$ que pasó a asumir la dirección intelectual y moral del país.

En el primero de estos planos, destacó la marcada recuperación del gasto público militar y de seguridad provocados por la guerra contra el terrorismo islámico y, sobre todo, las intervenciones armadas en Medio Oriente, que revertió fuertemente la ten-

24 El nuevo conservadurismo intelectual de EU de fines del siglo XX fue muy distinto al conservadurismo populista-aislacionista de Pat Buchanan y la derecha republicana de los años setenta, en la medida en que vinculó la seguridad internacional del país a la creación de regímenes políticos nacionales afines a las instituciones y valores estadounidenses, haciendo caso omiso del derecho y la organización internacional vigente, y del mantenimiento de la paz. Tal concepción, desarrollada originalmente por el filósofo político de origen alemán Leo Strauss, fallecido en los años setenta, se extendió ampliamente en los principales círculos de poder del país, y se fortaleció por la adición del componente militar incorporado por Albert Wohlstetter, el teórico de la guerra limitada con armas "inteligentes" de extraordinaria precisión, y con el desarrollo de una industria bélica altamente innovadora. Parte fundamental de la política internacional de esta nueva derecha fue el apoyo incondicional a Israel y a su política regional subimperialista, vista como bastión fundamental de la difusión del capitalismo neoliberal en Medio Oriente. Ésta es una de las razones fundamentales por las que se jerarquizó la invasión del Irak de Sadam Hussein (que carecía de vínculos importantes con el fundamentalismo islámico), por encima, incluso, de la intervención en Afganistán, mucho más vinculada al combate contra Al Qaeda. 
dencia contraria que siguió en el fin de la guerra fría durante los gobiernos de Clinton. En el ámbito interno, sobresalieron las reducciones generalizadas de impuestos para los ricos y capas medias promovida por Bush, convertidas en instrumentos proselitistas fundamentales para la preservación de la base política del Partido Republicano, en un país donde sólo participaba no más de $40 \%$ de la población en los procesos electorales.

El conjunto de lo expuesto dio lugar a una sucesión de grandes déficit fiscales que se tradujeron en montos crecientes de endeudamientos público y externo, fuertemente relacionados entre sí. En 2007, tales déficit crecieron a niveles muy grandes, sobre todo en relación con el producto bruto interno del país: cerca de 10,500 billones de dólares de deuda pública (76\% del PIB) que se estima alcanzarán en 2008, incluyendo la deuda privada, a bastante más de 16,300 billones de duda externa total, que es una cifra muy superior al PIB estadounidense.

Ambos factores implicaron una fuerte dependencia financiera en relación con las naciones asiáticas acreedoras, sobre todo de Japón, China y los países petroleros de Medio Oriente, que fue un factor acentuado considerablemente en 2008 con el impacto de la crisis económica.

El resultado de todo ello, en conjunción con las políticas monetarias de la Reserva Federal desde la crisis de 2001-2002, fue el desmoronamiento del valor internacional del dólar a niveles jamás alcanzados: 1.5 de dólar por euro hacia mediados de 2008 frente a una relación de uno a uno en los primeros años de la década, que comenzó a revertirse en la segunda mitad de 2008. ${ }^{25}$ El derrumbe del dólar tuvo una enorme importancia mundial, en la medida en que el dólar es la principal moneda mundial de reserva y la base del actual sistema monetario internacional, que es un fenómeno que parece haber entrado en franca declinación a partir de su depreciación, según el reconocimiento del propio Fondo Monetario Internacional.

En política internacional, el gobierno de EU debió pagar los costos económicos, políticos y militares de su cruzada mundial contra el fundamentalismo islámico, las intervenciones militares en Irak y Afganistán, el respaldo incondicional a Israel en el

25 En los meses finales de 2008, el dólar comenzó a recuperar parte de su valor hasta alcanzar en diciembre cerca de 1.3 por euro. Pero esta recuperación parece ser un fenómeno coyuntural, producto de la conjunción de factores como la entrada de Europa en la crisis financiera con la consiguiente desvalorización del euro, el pánico de los inversionistas internacionales que se refugiaron en los bonos de largo plazo del gobierno estadounidense o la repatriación de fondos desde el exterior por transnacionales estadounidenses desesperadas ante la imposibilidad de obtener financiamiento interno en EU. 
conflicto con el mundo árabe o la cruzada diplomática contra Irán. Una cuestión central en este sentido es la crisis de las organizaciones internacionales como el FMI, la Organización Mundial de Comercio (OMC) o las propias Naciones Unidas vinculadas directamente a la hegemonía internacional de EU. ${ }^{26}$ Habría que agregar el colapso de las políticas neoliberales impulsadas por Estados Unidos en América Latina y otros países en desarrollo, como el fracaso del Área de Libre Comercio de las Américas (ALCA), el rechazo casi generalizado del Consenso de Washington (Stiglitz, 2006) o la crisis del pensamiento económico oficial (ortodoxia neoclásica), cada vez más afectado por su imposibilidad para explicar los cambios de la economía mundial y la crisis financiera emergente. Además de la creciente dependencia energética de EU de países actual o potencialmente hostiles como los del mundo islámico, Rusia o Venezuela.

\section{El ascenso mundial de China y las otras grandes naciones emergentes}

El gran salto hacia adelante de China y otros grandes países en desarrollo como India, Rusia, regiones integradas como la Asociación de Naciones del Sudeste Asiático, en la que destaca Vietnam como el país de más rápido desarrollo económico, Medio Oriente o los avances de las naciones más dinámicas de América del Sur o Sudáfrica, ha permitido a los mismos entrar en una nueva etapa de evolución económica mucho más intensiva en tecnología avanzada, conocimientos e intensidad de capital, expresada en tasas más elevadas de crecimiento económico, desarrollo interior y competitividad internacional. Como resultado de lo expuesto, la evolución económica mundial siguió una nueva dinámica, que implicó un cambio histórico muy importante en relación con los años finales del siglo pasado, como ya se pudo ver en el cuadro 3 sobre el producto interno de las principales regiones del mundo, respectivamente.

A diferencia del lento crecimiento de las exportaciones de EU de $6.2 \%$ entre 2000 y 2007 (11\% a partir de 2003) muy por debajo de las de Unión Europea de 11.9\% (15.1\% a partir de 2003), así como de su pérdida de posiciones relativas dentro co-

26 El FMI, por ejemplo, tras sus enormes fracasos en Asia Oriental y Rusia, sustituyó sus políticas de ajuste aplicadas durante los años noventa (defensa de los acreedores y grandes rescates de los deudores) por políticas erráticas carentes de rumbo, completamente rebasadas por fenómenos como la crisis o la negativa argentina a pagar más de 25\% de su deuda externa (Dabat, 2004 y 2005). Por su parte, la OMC ha quedado completamente rezagada respecto de los grandes cambios de la economía mundial que impone la globalización, como la protección a la propiedad intelectual, exigida por países industrializados o las exigencias de países en desarrollo por terminar con los subsidios a las exportaciones agrícolas de los países desarrollados. 
mercio mundial, las regiones y países emergentes mencionadas presentan tasas mucho más elevadas de crecimiento de sus ventas externas. En el caso de China, las exportaciones crecieron a una tasa media de $25.8 \%$ anual entre 2000 y 2007 y $30.3 \%$ entre 2003 y 2007, mientras que las de India y Rusia lo hacen a tasas de $24.2 \%$ y $27.2 \%$ respectivamente, entre los dos últimos años mencionados (OMC, 2007).

$\mathrm{Al}$ creciente peso comercial de los países emergentes encabezados por China debe agregarse la importancia de sus grandes empresas transnacionales nativas que juegan un papel fundamental en el comercio exterior de estos países y han comenzado a incorporarse a las listas más reconocidas de las principales firmas del mundo (Dabat y Ordóñez, en prensa). Tales grandes compañías privadas, junto a las públicas, a las filiales de las empresas transnacionales radicadas en esos países y a las grandes joint ventures con participación pública, estarán entre las principales bases del boom exportador.

Otra cuestión central será la creciente capacidad financiera de esos países, resultante de los grandes superávit comerciales, reservas nacionales en divisas y los diversos instrumentos de manejo internacional de las mismas. Respecto de las reservas de divisas, como hemos visto, destaca ampliamente el lugar de China con reservas superiores a los dos mil millones de dólares en 2008, y su papel ya señalado de gran acreedor de Estados Unidos. Pero se trata de un fenómeno mucho más general traducido en indicadores como la balanza de cuenta corriente, la naturaleza del financiamiento externo o la acumulación general de reservas de los países en desarrollo (véase el cuadro 4).

El principal instrumento activo de movilización y valorización de los excedentes externos acumulados serán los llamados fondos soberanos, constituidos sobre todo por los países petroleros islámicos, por China y otros países de Asia Oriental

Cuadro 4

Balanza de cuenta corriente y financiamiento externo de las PED (miles de millones de dólares)

\begin{tabular}{lccc}
\hline & 1996 & 2000 & $2006^{*}$ \\
\hline Balanza de cuenta corriente & -85 & 88 & 494 \\
Financiamiento externo & 339 & 243 & 393 \\
$\quad$ Inversión directa & 129 & 168 & 223 \\
$\quad$ Inversión financiera & 123 & 42 & 93 \\
Acumulación de activos & 254 & 331 & 887 \\
$\quad$ Sector público (reservas) & 81 & 111 & 612 \\
Sector privado & 173 & 220 & 275 \\
\hline
\end{tabular}

Fuente: Fondo Monetario Internacional. Word Economic Outlook.

* Pronósticos para 2006. 
Cuadro 5

Principales fondos federales

\begin{tabular}{|c|c|c|c|c|}
\hline País & Nombre & $\begin{array}{c}\text { Actos } \\
\text { (Mn \$) }\end{array}$ & $\begin{array}{l}\text { Año de } \\
\text { creación }\end{array}$ & Origen \\
\hline Emiratos Árabes Unidos & Abu Dhabi Investment Authority (ADIA) & 875 & 1976 & Petróleo \\
\hline Singapur & Government of Singapore Investment Corporation (GIC) & 330 & 1981 & Otros \\
\hline Noruega & Government Pension Fund-Global (GPFG) & 322 & 1990 & Petróleo \\
\hline Arabia Saudí & Varios & 300 & NA & Petróleo \\
\hline Kuwait & Kuwait Investment Authority (KIA) & 250 & 1953 & Otros \\
\hline China & China Investment Compañy Ltd. & 200 & 2007 & Petróleo \\
\hline Hong Kong & Hong Kong Monetary Authority Investment Porffolio & 140 & 1998 & Petróleo \\
\hline Rusia & Stabilization Fund of the Russian Federation (SFRF) & 127 & 2003 & Otros \\
\hline China & Central Hujin Investment Corp. & 100 & 2003 & Otros \\
\hline Singapur & Temasek Holdings & 108 & 1974 & Otros \\
\hline Australia & Australian Government Future Fund (AGFF) & 50 & 2004 & Petróleo \\
\hline Libia & Reserve Fund & 50 & NA & Petróleo \\
\hline Qatar & Qatar Investment Authority (QIA) & 40 & 2000 & Petróleo \\
\hline Estados Unidos & Alaska Permanent Reserve Fund Coperation (APRF) & 40 & 1976 & Petróleo \\
\hline Brunei & Brunel Investment Agency (BIA) & 35 & 1983 & Otros \\
\hline Irlanda & National Pensions Reserve Fund (NPRF) & 29 & 2001 & Petróleo \\
\hline Argelia & Reserve Fund & 25 & NA & Otros \\
\hline Corea del Sur & Korea Investment Corporation (KIC) & 20 & 2006 & Otros \\
\hline \multicolumn{5}{|c|}{ Prinipales fondos en construcción } \\
\hline China & State Foreign Exchange Investment Corporation (SFEIC) & 200 & 2007e & Otros \\
\hline Rusia & Future Generations Fund of the Russian Federation (SFRF) & 32 & $2008 \mathrm{e}$ & Petróleo \\
\hline
\end{tabular}

Total de montos involucrados $3.422,00$

Fuente: D8 Research.

e: estimación.

como Singapur, por Rusia y por algunos pocos industrializados incluido el estado de Alaska, en Estados Unidos. El cuadro 5 muestra una lista de los principales fondos petroleros entre los que destaca el de Abu Dhabi por su enorme volumen. Pero también en este rubro resulta muy importante la participación de los fondos chinos que, sumados al fondo de Hong Kong, presentan una cantidad bastante superior a los 600 mil millones de dólares.

Otra cuestión relevante para el futuro orden mundial es el mayor peso económico mundial que han comenzado a tener las relaciones intrarregionales de los países en desarrollo, que se manifiesta tanto en los acuerdos de integración regional como en la orientación del comercio internacional entre diferentes países en desarrollo o comercio sur-sur, como puede verse en la gráfica 6 . De entre esos procesos se destaca la fuerte tendencia hacia el proceso gradual de integración regional del este y el sur de 
Asia, que de hecho empezó a manifestarse en torno al mercado chino y ya tiene importantes amarres en términos de integración formal. ${ }^{27}$ Este proceso condujo a un giro gradual del comercio exterior en países como Japón, Corea o los países de la ASEAN, del mercado estadounidense hacia el mercado chino, así como la creciente vinculación del mismo con India. La progresiva integración de Japón, Singapur, Corea y Taiwán contribuyó productivamente para lograr altos niveles tecnológicos en estos países. Lo mismo sucede con los procesos sudamericanos de integración regional a variados niveles (comercial, financiero, energético), o las relaciones de Rusia con los países de Asia Central vinculados a la Comunidad de Estados Independientes, o a las de China, Rusia o India con África o Sudamérica, o al fortalecimiento de los países islámicos de Medio Oriente o de Sudáfrica como parte de una importante dinamización económica de gran parte de África.

Gráfica 6

Exportaciones de las economías emergentes \% incremento con respecto al año anterior

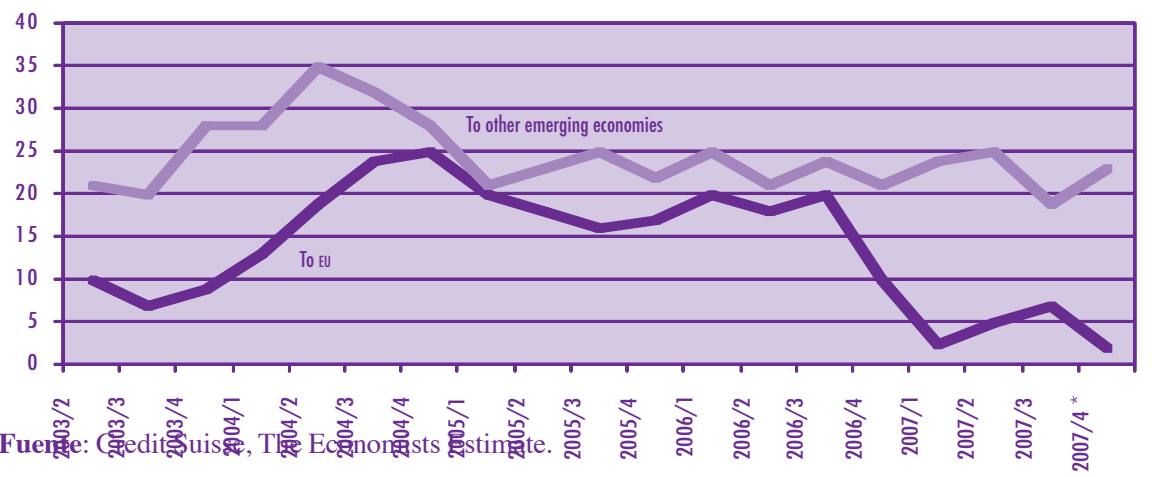

Al papel económico crecientemente importante de los países emergentes dentro del orden mundial habría que agregar el efecto demostración que podrían llegar a tener las características de las instituciones económicas y sociales y las políticas de

27 El proceso de integración económica formal de Asia Oriental comienza en 1999 con el acuerdo de cooperación ASEAN Plus Three (Japón, China y Corea) que aún opera hasta ahora e impulsa diversos tipos de proyectos. Los acuerdos de liberación comercial que se sucedieron desde entonces fueron los de Japón y Singapur (2002), ASEAN y China (2005), Corea, Singapur (2005 y ASEAN y Corea, 2006), hallándose en trámite los de ASEAN y Japón, y Japón y Corea ( Lee, 2008). La incorporación de India a este proceso es mucho más reciente y ha comenzado a darse a partir de acuerdos con países de la ASEAN, pero no ha podido superar todavía las viejas diferencias geopolíticas con China (Parker y Shaffer, 2008). 
desarrollo de las naciones más grandes y de mayor peso económico y político de esos países. Tales instituciones corresponden a economías reguladas de mercado y apertura a la globalización productiva, con estrategias de desarrollo muy diferentes a las preconizadas por el neoliberalismo como un fuerte activismo estatal, poderosas empresas públicas y grandes firmas privadas exportadoras muy competitivas, grandes mercados internos en desarrollo, amplias políticas de educación, salud y seguridad social, fuertes reservas de divisas y débil exposición a los aspectos más especulativos del sistema financiero privado.$^{28}$ Aparte del complejo tipo de economía mixta prevaleciente en China, o del tipo de reestructuración estatista del capitalismo ruso con Vladimir Putin, en ese sentido destaca el ejemplo menos conocido de India en su etapa de mayor crecimiento económico (a partir de 2004), con el gobierno centro-izquierdista modernizador del Partido del Congreso en alianza con el Partido Comunista de India y otras fuerzas comunistas, socialistas y progresistas (Alianza Progresista Unida). India no sólo se caracteriza por los grandes grupos empresariales privados como Tata o Birla, sino también por el control estatal de $40 \%$ de los activos bancarios, más de $80 \%$ de la infraestructura, la electricidad, el petróleo y la telefonía y de $48 \%$ del conjunto de la empresa moderna (Gupta, 2007). También es el país que la OCDE considera (The Economist, 2007) el más protector del trabajo. ${ }^{29}$

Podríamos concluir en que la relocalización de la producción hacia países de bajos costos laborales y niveles educativos relativamente altos (desde la lógica de mayor competitividad internacional por costos laborales unitarios más bajos y políticas públicas activas de desarrollo) ha provocado el desplazamiento gradual del centro cíclico mundial desde Norteamérica hacia Asia Oriental, así como un creciente peso dentro de la economía mundial de los países en desarrollo más importantes. Como

28 Salvo el caso de Brasil, con un gran mercado de derivados (Bank For International Settlements, 2007), el peso de los nuevos instrumentos financieros pesa bastante menos en los demás países. Todos ellos cuentan con sistemas bancarios muy regulados y en gran parte públicos, débil profundización e internacionalización financiera y grandes reservas internacionales de divisas (Lane y Schmukler, 2007). Tales factores amortiguan sensiblemente la difusión de los mecanismos generados por el nuevo sistema financiero.

29 Tal tipo de perfil de las grandes potencias emergentes tiene grandes similitudes con el de otros países exitosos de características muy distintas. Ése es el caso, por ejemplo, de naciones muy desarrolladas como Suecia o Finlandia (Dabat y Almanza, 2008), que también realizaron grandes reformas sociales a lo largo de su historia y tienen sectores públicos muy fuertes. También en buena medida de Corea o Taiwán, de los países dinámicos de América del Sur o, sobre todo, de Vietnam, el país de Asia Oriental que sigue a China en dinamismo económico, que ha comenzado a incorporarse a la economía del conocimiento y ya cuenta con sectores productivos de alta tecnología, como la industria de semiconductores. 
consecuencia de ello, la mayoría de estas naciones tiende a vincularse crecientemente con los mercados asiáticos como resultado de la complementación económica generada por la enorme demanda internacional de materias primas y alimentos de Asia Oriental (países con exceso de población y escasez relativa de recursos naturales) y los abundantes recursos de este tipo existentes sobre todo en América del Sur y África.

Aunque no todos los países en desarrollo se encuentran en esta situación, todos (incluido desde luego México) tienen que afrontar de la mejor manera las posibilidades planteadas por la crisis de hegemonía de Estados Unidos, la diversificación de los centros de poder mundial, los cambios en los términos de intercambio internacional y la entrada en escena de un nuevo tipo de estrategias de desarrollo como del tipo de formuladas por los países de Asia Oriental, a partir del impulso al sector público, el desarrollo socioeducacional o el aprendizaje tecnológico, conjugando la integración competitiva en la globalización con el desarrollo de los mercados internos nacionales y la inclusión social de la población en camino a la construcción de economías modernas de conocimiento.

En ese sentido, resulta fundamental tomar como referencia la experiencia vivida por la América Latina de la segunda posguerra, cuando dejó pasar una coyuntura internacional muy favorable por embarcarse en políticas nacionalistas y populistas de corto plazo, que hicieron a un lado, lo cual no dejó la formular estrategias de desarrollo de largo plazo, basadas en el elevamiento generalizado de la capacidad productiva de la población (educación, salud, inclusión e iniciativa social) y la integración en la economía mundial.

\section{Principales conclusiones}

Las diferentes cuestiones consideradas en el presente trabajo conducen a por lo menos cinco grandes conclusiones, que pasamos a exponer a continuación.

La primera tiene que ver con la naturaleza histórica de la crisis y de su profundidad. ¿Estamos ante una crisis terminal de las bases tecnoproductivas del nuevo capitalismo surgido de la revolución informática y la globalización, como fue el caso de la gran depresión de los años treinta del siglo pasado en relación con el capitalismo monopolista-financiero clásico nacido a fines del siglo XIX? ¿O estamos más bien ante una crisis de desarrollo del capitalismo informático global, que contrapone su base productiva a su superestructura financiera e institucional neoliberal de origen, especialmente en el país que dirigió y modeló el proceso en su primera etapa histórica de desarrollo? Nuestra respuesta va en esta segunda dirección, si partimos de la idea 
de que la profundidad y duración del derrumbe internacional por venir dependerá sobre todo de la continuidad y profundización de la revolución informática, ${ }^{30}$ de la integración tecnoeconómica que logre alcanzar con la revolución energética en ciernes (e implícitamente con la crisis ambiental), y de cómo logre superar adecuadamente tanto el lastre de su superestructura financiera-especulativa como, en general, el régimen socioinstitucional del neoliberalismo.

La segunda conclusión tiene que ver con la extensión y duración mundial de la crisis. Al respecto consideramos que el elemento clave es la medida en que China, sobre todo, y más en general Asia Oriental (incluyendo India) logren resistir relativamente el embate de la crisis ${ }^{31}$ y acentuar su papel de locomotora económica emergente en el ámbito mundial. Debe partirse del hecho de que el nuevo papel económico mundial de esta última región la convierte en una fuerza contracíclica mundial extraordinaria que, contradictoriamente, al mismo tiempo que acelera la crisis de hegemonía mundial de Estados Unidos, ayuda a la recuperación económica de este último país por medio de diferentes mecanismos.

La tercera conclusión se referiere a la extensión internacional de la crisis. Conforme se plantea en el trabajo, los más afectados serán los más expuestos a las relaciones comerciales y financieras con Estados Unidos, a los nuevos mecanismos y agentes financieros (desregulación, instrumentos derivados y colaterales, etcétera) y al financiamiento externo de los países industrializados. Los menos expuestos serán los que cuenten con Estados nacionales y sistemas bancarios fuertes, reservas internacionales más importantes en relación con el PIB nacional, mercados internos y regionales más amplios, mayor capacidad de autofinanciamiento mediante mecanismos fiscales in-

30 En ese sentido, y a pesar de las diferencias señaladas en la primera sección de la primera parte de este trabajo, la actual crisis tiene muy importantes puntos de contacto con la anterior. La de 2001-2002 tuvo que ver con un problema crucial para el desarrollo del capitalismo informático, como fue en su momento la tendencia al agotamiento de la ley de Moore (continuidad del proceso de miniaturización, complejidad y abaratamiento del semiconductor), que pudo superarse por la entrada en acción de la nanotecnología (Dabat, 2008 y Dabat y Ordóñez, 2009). La crisis actual también está vinculada a otro tipo de obstáculo que limita la continuidad y profundización de la revolución informática, como es el caso tanto de la superestructura financiera e institucional de inicio de la misma, como de la cada vez más débil base energética en que se apoyó hasta ahora, basada en los combustibles fósiles no renovables y contaminantes. La remoción de tales obstáculos requieren, en ambos casos, un nuevo tipo de reestructuración institucional y tecnoeconómica que posibilite el despliegue a un nivel más amplio de las potencialidades de las nuevas tecnologías.

31 Nos estamos refiriendo a una disminución no muy grande de sus tasas insostenibles de crecimiento y comercio exterior (pasa, por ejemplo, de tasas de $11 \%$ y $30 \%$, a otras más moderadas de $7-8 \%$ y $20-25 \%$, o a sólo breves caídas de mayor dimensión). 
ternos, así como el acceso nacional a las rentas económicas extraordinarias derivadas del comercio internacional (Dabat, Rivera y Sztulwark, 2007).

La cuarta conclusión apunta al futuro y a las formas espaciales e institucionales de la globalización. ¿Estamos ante una crisis terminal misma o ante un cambio histórico de su modalidad de desarrollo? Se trata de una cuestión vinculada directamente a la primera conclusión, en la medida en que la globalización es, en lo fundamental, la configuración espacial del nuevo tipo de capitalismo surgido de la revolución informática (Dabat, 2002). Por tanto, conforme hemos planteado en otros trabajos (Dabat, 2005, por ejemplo) y en este mismo material, la crisis de Estados Unidos y de su modalidad nacional de capitalismo no implicará el fin de la globalización ni cambios mundiales que apunten tanto al fortalecimiento de los procesos de integración regional y de regulación internacional, como al desplazamiento del centro cíclico de la economía mundial hacia Asia Oriental, y a reformas socioinstitucionales nacionales y regionales, más acordes con las del tipo de economía de los países emergentes exitosos más importantes.

Finalmente, una quinta conclusión conduce al lugar en que se encuentra Estados Unidos en la economía mundial y el orden internacional, y a sus perspectivas futuras como país. A pesar de su crisis, EU sigue siendo la nación más poderosa, rica e influyente del mundo, especialmente por su capacidad tecnológica, empresarial, militar y de involucramiento en la arena mundial. Pero ya no como única superpotencia hegemónica $^{32}$ capaz de imponer unilateralmente sus propios objetivos al mundo. Ello la obligará a reconocer las nuevas relaciones mundiales de fuerza y a emprender grandes reformas en el sentido ya esbozado por el gobierno de Obama. Tales reformas vivificarán su economía a mediano plazo, generarán importantes logros en energía, infraestructura o ambiente y restablecerán gran parte de su competitividad internacional. Pero ello será a costa de una colosal deuda externa y de una reducción del nivel

32 Según Gramsci, hegemonía significa poder (sea militar, económico o político), y también capacidad de liderazgo en las cuestiones más importantes de una comunidad política (en este caso el orden internacional). Capacidad de liderazgo, a su vez, implica políticas que apunten de alguna manera a la resolución de los principales problemas de dicha comunidad, así como también capacidad práctica para imponerla en los hechos, no sólo por medios político-institucionales, económicos o militares, sino también capacidades culturales, vistas como superioridad relativa de determinados aspectos de la cultura del país hegemónico en aspectos centrales del desarrollo de las naciones. En las actuales condiciones históricas, tal tipo de peso internacional implica bastante más que el nivel científico-tecnológico de las universidades o la extensión internacional de la lengua del país dominante (en este caso la inglesa), como es también el nivel de la cultura ambiental o del respeto a los derechos humanos, civiles o de autodeterminación de otros pueblos. 
neto de ingresos de su población, dentro de un mundo multipolar al que no pondrá imponer ya unilateralmente sus intereses nacionales.

Habría que agregar que las complejas condiciones de nuestro tiempo (globalización, crisis ambiental, crisis energética, crisis alimentaria, etcétera) así como la de la hegemonía de Estados Unidos plantean la necesidad de avanzar hacia un nuevo orden mundial multicéntrico, lo que por cierto no será una tarea fácil, no sólo por la resistencia de las fuerzas económicas, financieras y militares beneficiarias del actual orden mundial, sino también por la inmadurez o las limitaciones de las nuevas potencias emergentes para liderar ese cambio. ${ }^{33}$ Junto a ello, se planteará también la necesidad de revertir sustancialmente la orientación neoliberal de las ideas e instituciones que dominaron el escenario económico y político mundial en las últimas décadas, por otras mucho más acordes con los requerimientos tecnológicos, económicos, sociales y ambientales del mundo. ${ }^{34}$

33 Éste es, sobre todo, el caso de China, la gran potencia mundial emergente, cuya política internacional ha estado orientada hasta ahora hacia el aprovechamiento de las condiciones internacionales anteriores para su propio crecimiento, con preocupaciones mucho menores sobre el futuro del mundo y el papel dirigente (en sentido de codirección) que el país debería jugar dentro del nuevo orden mundial. Ello no sería igual en el caso ruso, pero habría que agregar que Rusia no está en condiciones objetivas de cumplir un papel tan importante como el de China dentro del nuevo orden mundial.

34 En Dabat (2009) se señala que el pleno aprovechamiento de las potencialidades de la revolución informática requiere de la ampliación de los espacios públicos, tanto en el ámbito tecnoeconómico como socioambiental, para dar respuesta a los crecientes requerimientos de infraestructura moderna, investigación básica, educación y aprendizaje en general, gasto social y reconstrucción ambiental que presupone la llamada economía del conocimiento. 
Association of Financial Guaranty Insurers, "Asset-Backed Securities", Nueva York, AFGI, 2008: http://afgi.org/products-assetsec.htm.

Atkinson, Robert, "Understanding the offshoring challenge", Policy Report, Working Paper, Washington Progresive Policy Institute, 24 de mayo de 2004, pp. 1-23.

Ballabriga, Fernando y Xavier Mena, "Análisis y previsión de la coyuntura económica de la zona euro", Informe económico ESADE, primer semestre 2008, Barcelona, ESADE BPMO Editgroup, pp. 9-49.

Baller, Jim y Casey Lide, "American Needs a Fiber-Based National Broadband Policy Now. If not Sooner", The FTTH Prism, vol. 3, núm. 2, Washington, The Baller Herbst Law Group, octubre de 2006, pp. 1-8.

Bank for International Settlements, Triennial central bank survey of foreingn exchange and derivatives market activivity in 2007Final result, treinal surveys, 2008: http:// www.bis.org/publ/rpfxf07t.htm.

Barr, Alistar, "Brokers threatened by run on shadow bank system", Market Wacht, San Francisco, EDT, 20 de junio 2008: http:// www.marketwatch.com/news/story/bigbrokers-threatened-crackdown-shadow/ story. aspx ? guid=\%7BFA23DF5A-918F41DA-B794-7E553ADAFAA7\%7D.

Board of Governors of the Federal Reserve System, Financial Services Fact Book, Nueva York, Insurance Information Institute, The Financial Services Roundtable, 2008.

Bussines Wire, "Worldwide PC Microprocessor Market Hits Record Levels of Unit Shipments Again in 3Q08, But Outlook for Market Has Grown Murky, According to IDC", Business Publications, San Mateo California, 3 de noviembre de 2008: http:// findarticles.com/p/articles/mi_m0EIN/is_ 2008_Nov_3/ai_n30958098/.

Cox, Robert y Sinclair Timothy, Approaches to World Order, Cambridge, Studies in International Relations, 1996.

Dabat, Alejandro y Sergio Ordóñez, Revolución informática, nuevo ciclo industrial e industria electrónica en México, México, IIEc-UNAM, 2009.

y Orquídea, Melo, "La crisis histórico estructural de Estados Unidos y sus consecuencias mundiales", Economía Informa, núm. 352, México, UNAM-FE, mayo- junio de 2008, pp. 7-19.

y Silvia Almanza, Dossier sobre Finlandia, vol. 2, PROGLOCODE, México, 2008.

, Miguel Ángel Rivera Ríos y Sebastián Sztulwark, "Rentas económicas en el marco de la globalización: desarrollo y aprendizaje / Implicancias para América Latina”, en Problemas del Desarrollo, vol. 38, No 151, México, UNAM-IIEc, octubre-diciembre 2007, pp. 11-36.

y Alberto Morales, "Notas sobre los grandes cambios de la economía y el orden mundial a comienzos de siglo", Economía Informa, núm. 348, México, UNAM-FE, septiembre-octubre, 2007, pp. 6-25.

, "Globalización, neoliberalismo y hegemonía. La primera crisis de la globalización y sus perspectivas", Aragonés Ana María (coord.), Globalización: retos y perspectivas, México, en prensa.

, "Globalización, capitalismo actual y configuración espacial del mundo", en Basave, Jorge, Alejandro Dabat y otros, Globalización y alternativas incluyentes para el siglo XXI, México, Porrúa-IIE,CRIM-FE, UNAM-UAM, 2002.

Deffree, Suzanne, "Financial crisis will cost semiconductor market more than $\$ 25 \mathrm{~B}$ in 2009, Gartner reports", Electronic News, news-electronic news, 11-marzo-2008: http://www.edn.com/article/CA6610813. html.

Domain-b.com, "Value of global financial assets outpaces GDP growth: McKinsey report", 28 de enero 2008: http://www.domainb.com/companies/companies_m/McKinsey/ 20080128_mcKinsey.html.

Economist Inteligence Unit, "George Bush's subprime rescue plan", The Economist. com, 7 de diciembre de 2007.

Ernst, Dieter, "The new geography of innovation and US comparative competiveness", Western Economics Association International, $83^{\text {rd }}$ conference, Honululu, 2 julio de 2008.

Euromoney, "Private banking Management Suvrey 2008: The benchmark annual Survey of the wealt management industry", 8 de enero 2008. http://www.euromoneyjobs. $\mathrm{com} /$ Article/1786822/Private-banking- 
and-wealth-management-survey-2008The-benchmark-annual-survey-of-thewealth.html.

European Commission, Towards a European strategy form nanotechnology, Communication from the Commision, Bruselas, Unión Europea, 2004.

European Patent Office, "Nanotechnology in European patents. Change an opportunity", http://epo.org/topics/issues/nanotechonology.html.

Gereffi, Gary, Vivek Wadhwa y Ben Rissing, "Enmarcando el debate sobre subcontratación de ingeniería: comparando calidad y cantidad de los ingenieros craduados en Estados Unidos, India y China”, en Dabat Alejandro y Jesús Rodríguez (coord.), Globalización, conocimiento y desarrollo, La nueva economía global del conocimiento. Estructura y problemas, México, PorrúaUNAM, 2009.

Hullmann, Angel, The Economic development of nanotechnology. An indicators based analysis, European Comisión, 28 noviembre de 2006. ftp://ftp.cordis.europa.eu/pub/ nanotechnology/docs/nanoarticle_hullmann_nov2006.pdf

La Nación, "Soros cree que es el fin del dólar como moneda de reserva", Economía, Buenos Aires, 24 de enero 2008: http://www.lanacion.com.ar/nota.asp?nota_id=981429.

Lane, Philip y Sergio Schmukler, "The International Financial Integration of China and India", Working Papers, núm. 4132, San Francisco, Federal Reserve Bank of San Francisco, http://ideas.repec.org/a/fip/fedfpr/y2006ijunx8.html.

Lee, Hiro, y Dominique Vander Mensbrugghe, Regional Integration, Sectorial Adjustment and Natural Grouping in East Asia, Osaka, OSIPP Discussion Paper, núm. 07E008, Osaka University, 2007.

Lux Research, The Nanotech Report 2004, Investment Overview and Market Research for Nanotechnlogy, Nueva York, Lux Research Inc., 2004

Marshall, Wesley, "Rescatando amigos: lecciones del rescate bancario mexicano para Estados Unidos", Economía Informa, núm. 356, México, FE-UNAM, enero-febrero 2009, pp. 144-160.

Nandini, Gupta, Partial Privatization and State-Ownership in India, Indiana. The World Bank, Kelley School of business, Indiana University, 24 de mayo de 2007.
NYSE, “Index Dow Jones y Nasdaq”, a noviembre de 2008, Nueva York, 2008, http:// www.djindexes.com.

OMC, "Times series on merchandise and commercial services trade, Exports and Imports”, 2007, http://www.wto.org/spanish/ docs_s/docs_s.htm.

Ordóñez, Sergio, "La industria de servicios de telecomunicaciones en la crisis actual: Estados Unidos y México", ponencia presentada en el Seminario de Economía Méxicana, IIEc-UNAM, México, 20 de noviembre de 2008.

Parker, Elizabeth y Teresita Shaffer, "India and China: The Road Ahead", Center For Strategic \& International Studies, Nueva York, 1 de julio, 2008. www.csis.org/medis/csis/ pubs/sam120.pdf.

Pazarbasioglu Ceyla, Mangal Goswani y Jack Ree, "La nueva cara de los inversores", Finanzas y Desarrollo, Dialnet, marzo, 2007, www.imf.org/external/pubs/fannd/ spa/2007/03pdf/pazar.pdf.

Pérez, Carlota, Revoluciones tecnológicas y capital financiero, México, Siglo XXI, 2004.

Porter, Michael, On Competition, Hardward Businesse Review Book, chapter 13, Capital disadvantage: America's Failing Capital Investment System, Nueva York, 1998.

Rubini, Nouriel, "A coming recession in the US economy”, 17 de julio 2006, www.rgmonitor.com.

Sargent, John F., "Nanotechnology and US Competitiveness", CRS Report for Congress, Order Code RL34493, Congressional Researchs Service, 15 de mayo 2007, pp 1-30: http://www.fas.org/sgp/crs/misc/ RL34493.pdf.

Stiglitz, Joseph , Globalization and its Discontents, Nueva York, Norton \& Company Inc., 2006.

Tassell, Tny, "If it makes money, measure it", FT.com, Wealt Mutual funds, 2006, www. ft.com $/ \mathrm{cms}$.

Tett, Gillian y Paul Davies, "Out the Shadows: How banking's secret system broke down", Financial Times, 16 de diciembre 2007: http://www.ft.com/cms/s/0/ 42827c50-abfd-11dc-82f0-0000779fd2ac. html?nclick_check=1.

Tett, Gillian, "The World in 2008", http://www. ft.com/cms/s/2/a39a93f8-1f72-11de-a7a500144feabdc0,dwp_uuid=590f3c26-456411da-981b-00000e2511c8.html.

The Economist, Getting worried downtown, The Economist.com, 15 de Noviembre 
2007: http://www.economist.com/opinion/ displaystory.cfm?story_id=10134077.

The Economist, Of Froth and fundamentals, The World Economy, The Economist.com, 9 de octubre 2008: http://www.economist. com/research/articlesbysubject/displaystory.cfm? subjectid $=7216688 \&$ story id $=12373732$.

The Wall Street Examiner, "Who Would Have Thought?", 2008: http://wallstreetexaminer.com.

Toledo, Alejandro, Nanotecnología: nociones básicas, importancia actual y alcances de una rama emergente de la economía del conocimiento. Resultado preliminar del proyecto de investigación "Nanotecnología: estado actual y perspectivas económicas, México, DCSH-UNAM, mimeo 2008.

UNCTAD, World Investment Report 2006, Nueva York and Geneva, United Nations publication, 2006.
United Nations, World Economic Situation and Prospect, NuevaYork, United Nations publication, 2008.

US Census Bureau, Statistical Abstract of the United States, Washington, US Census Bureau, 1998.

US Census Bureau, Statistical Abstract of the United States, Washinton, US Census Bureau. Table 1136, 2009.

US Department of Commerce, Real gross domestic product 1959-2007, Washington, Bureau of Economic Analysis, 2008: http://www.commerce.gov/NewsRoom/ TopNews/index.htm?ssMonth=09\&ssYea $\mathrm{r}=2007$.

Wilson, Jeff, Wall Street Grain Hoarding Brings Farmers, Consumers Near Ruin, Boomber Press, 2008: http://www.bloomberg.com.

World Trade Organization, Info Services on WTO and Trade issues, 13 de septiembre 2008.

\section{Desaarrofllo}

